This is the accepted version of the article published by Wiley Online : Sekyu Choi, S.; and
Fernández - Blanco, J. Worker Turnover and Unemployment Insurance, in International economic
review, June 2018. The final version is available at: https://doi.org/10.1111/iere.12322

\title{
Worker Turnover and Unemployment Insurance *
}

\author{
Sekyu Choi $\quad$ Javier Fernández-Blanco ${ }^{\ddagger}$
}

March 6, 2018

\begin{abstract}
This paper studies a competitive search model of the labor market with learning about matchspecific productivity in which risk-averse workers factor present and future unemployment risks in their search decisions. We examine internally efficient equilibrium allocations in which match termination occurs only if the joint value of a worker-firm pair is negative. Internal efficiency poses a trade-off between present and future risks. Public insurance provision also affects this trade-off, and, hence, worker turnover and job composition. In addition to unemployment benefits, the implementation of the planner's allocation requires a negative income tax and a zero layoff tax.
\end{abstract}

Keywords: Worker Turnover, Unemployment Risks, Competitive Search, Layoff Taxes, Internal Efficiency

*Previous versions of the paper have circulated under the title 'Unemployment duration and worker turnover'. We thank Jeff Campbell, Melvyn Coles, Jesús Fernández-Villaverde, Johannes Gierlinger, Nezih Guner, Joan Llull, Martí Mestieri, Espen Moen, Giuseppe Moscarini, Nicola Pavoni, Edgar Preugschat, José-Víctor Ríos-Rull, Robert Shimer, Kjetil Storesletten, Marcelo Veracierto, and Ludo Visschers for their feedback. We are also grateful to the editor Guido Menzio and three anonymous referees as well as numerous participants at the NBER Summer Institute 2014, REDg-Dynamic General Equilibrium Macroeconomics Workshop 2014, Mainz Workshop in Labour Economics 2014, Essex SaM Workshop 2014, SaM Annual Conference 2015, ESSIM 2015, and at various seminars. Sekyu gratefully acknowledges financial support from the Spanish Ministry of Economy and Competitiveness through grant ECO201232392 and through the Severo Ochoa Programme for Centres of Excellence in R\&D (SEV-2011-0075), and Javier from the Spanish Ministry of Science and Technology under Grant No. ECO 2013-46395, ECO2015-67602-P from MINECO/FEDER, UE, and from the Spanish Ministry of Economy and Competitiveness through the Severo Ochoa Programme for Centres of Excellence in R\&D (SEV-2015-0563).

${ }^{\dagger}$ University of Bristol

${ }^{\ddagger}$ Universitat Autònoma de Barcelona, Barcelona GSE and MOVE 
JEL Codes: J01, J08, J63, J65 


\section{Introduction}

From a job-seeker's perspective, a job consists of a list of items, including primarily a wage scheme and an expected duration. Regarding the latter, evidence shows that a large number of new matches are short-lived in the U.S. economy, which underscores the importance of future unemployment risks in workers' search decisions. In Choi and Fernández-Blanco (2016), using data from the Survey of Income and Program Participation, we document that over $42 \%$ of newly employed workers return to non-employment within a year, and this transition rate drops to $25 \%$ in the second year. Farber (1999) estimates these rates at 50\% and 33\%, respectively, using the National Longitudinal Survey of Youth.

The goal of this paper is to analyze the constrained efficiency of equilibrium hires and separations in a frictional economy with incomplete markets in which present and future unemployment risks are intertwined. Strikingly, the literature has mostly addressed the present and future risks separately. Regarding the present risks, a number of papers have studied the optimal design of unemployment insurance (UI). See e.g. Hopenhayn and Nicolini (1997), Shimer and Werning (2008) and, closest to ours, Golosov et al. (2013). Regarding employment protection policies, Blanchard and Tirole (2008) and Cahuc and Zylberberg (2008) show that the rationale underlying layoff taxes is to make firms internalize the welfare costs of dismissals, ${ }^{1}$ but do not consider the effects on job creation. Although both job-creation and -destruction margins are considered in Alvarez and Veracierto (2001), jobless workers do not take unemployment risks into account in the search process.

To this aim, we construct a two-period competitive search model of the labor market building upon Moen (1997), and model endogenous separations by introducing match-specific productivity as an experience good. ${ }^{2}$ All firms and workers are ex-ante identical. In period one, search takes place: firms compete for workers by committing to contractual offers, and risk-averse workers decide what sort of job to search for and the search intensity. Search is directed in the sense that offers promising a higher employment value attract more applicants. Upon meeting, a firm and a worker draw a match-specific productivity. This is unobservable in the first period, but is learned in the

\footnotetext{
${ }^{1}$ This is also the rationale for an experience rated UI system. See e.g. Feldstein (1978) and Wang and Williamson (2002).

${ }^{2}$ The experience feature was first introduced by Nelson (1970) meaning that the quality of a match can only be assessed by experiencing it. See also Jovanovic (1979).
} 
second period.

The unemployment risks are consumption risks because markets are incomplete, firms can only make payments to their own employees, and workers cannot self-insure by saving. As a result, risk-averse workers factor present and future unemployment risks in their search decisions. In equilibrium, as a result of the competition for workers, risk-neutral firms act both as employers and insurers of their employees as in the implicit contract literature. See Baily (1974) and Azariadis (1975). This is due to the difference in the ability to bear risk between workers and firms. There are two margins through which private markets may respond to workers' preferences: a job-creation margin and a match-termination margin. Regarding period-one unemployment risks, many low-wage jobs are posted in equilibrium to increase the employment chances of job-seekers, as in Acemoglu and Shimer (1999). ${ }^{3}$

We focus on equilibrium allocations in which period-two match-termination decisions are internally efficient, meaning that firms and workers resolve their coordination problems within the match and separation occurs if and only if the joint value of the match is negative. ${ }^{4}$ In addition to being a necessary condition to reach constrained efficiency, we argue that internal efficiency may result endogenously in equilibrium if either the contracting space is sufficiently wide or if an efficient negotiation process takes place. As the joint value is increasing in both the wage and the match-specific productivity, internal efficiency establishes a negative relationship between the wage and the productivity threshold that makes the joint value equal to zero. Therefore, job-seekers trade-off present and future unemployment risks. Moreover, public provision of insurance affects such a trade-off, and, hence, the equilibrium worker turnover.

To study the constrained efficiency of the equilibrium allocation, we compare it with the social planner's solution, i.e. the allocation that maximizes the expected discounted utility of the representative worker subject to the search and information frictions described above. The planner faces a moral hazard problem as workers' search intensity is unobservable. Because of workers' risk aversion, the planner attenuates the consumption difference between employment and unemployment in a way compatible with efficiently providing search incentives. As a result, the consumption of

\footnotetext{
${ }^{3}$ As Krishna (2009, Ch. 4.1) argues, this result also holds in first-price auctions with risk-averse bidders making higher bids because of the risk of losing.

${ }^{4}$ Indeed, we borrow the term of internal efficiency from the literature with on-the-job search. See Moen and Rosén (2004) and Menzio and Shi (2011).
} 
the unemployed is above their home production, which is their consumption level in the laissez-faire economy. The equilibrium is constrained inefficient: the consumption risks are not efficiently covered in the market economy because the sort of insurance markets offer against those risks makes job-creation inefficiently high and match-termination rates inefficiently low.

We show that the planner's allocation can be decentralized if a government sets an UI system funded by lump sum taxes to insure away the consumption risks. Our main result is that the implementation of the planner's allocation requires a negative income tax and a zero layoff tax. The rationale for this policy result is quite intuitive. The publicly-provided insurance crowds out the private provision of insurance. That is, the equilibrium wage and the productivity threshold both increase with unemployment benefits as workers play riskier job-search strategies. To incentivize job creation and discourage match-termination, firms must be subsidized, and although such subsidies could be set in various different forms, the efficient channel in a competitive search framework is through wages because contractual offers guide workers' search decisions. We show that the income tax rate must be such that the subsidy the firm obtains for not terminating the match is proportional to unemployment benefits. In sharp contrast with the Pigovian tax found in Blanchard and Tirole (2008), we show that layoff taxes must be zero because they distort not only match-termination, but also job creation in an inefficient way.

It is worth noticing that the publicly-provided unemployment insurance not only shapes worker turnover, but also job composition as both wages and output per worker increase with UI benefits. These effects are similar to the ones obtained in Acemoglu and Shimer (1999) and Golosov et al. (2013). ${ }^{5}$ The former show that a UI scheme induces firms to create more capital-intensive, higherwage jobs. In the latter, there are too few risk-averse workers seeking high-productivity jobs, and unemployment benefits (financed by increasing and regressive income taxes) allow workers to take riskier strategies in their job search. In our setting, average productivity increases with UI benefits because the insurance provided by low-productivity jobs is crowded out by the public provision of insurance.

We extend this normative exercise to an infinite horizon economy, and show that these policy

\footnotetext{
${ }^{5}$ Output per worker also increases with UI benefits in Marimon and Zilibotti (1999), Acemoglu (2001), and Teulings and Gautier (2004). Key differences with respect to these papers are their assumptions of risk-neutral workers, random search, and an exogenous separation rate independent of the match quality. We abstract from job-specific human and physical capital investments, which would enhance the welfare gains of turnover reducing unemployment benefits.
} 
results continue to hold. Then, we calibrate the model to match some salient features of the U.S. labor market, and compute the optimal policy that maximizes a steady-state utilitarian social welfare function. We find that unemployment insurance benefits are excessively generous, which is in line with Krusell et al. (2010). Furthermore, the optimal policy raises worker turnover, total output, output per worker and wages relative to the laissez-faire steady-state equilibrium.

Two standard assumptions in the literature on worker turnover are risk-neutral workers and random search. See e.g. Jovanovic (1984) and Moscarini (2005). Pinheiro and Visschers (2014) analyze an economy with random search and wage-posting, where firms are ex-ante heterogeneous in their termination rates and risk-neutral workers take into account wages as well as displacement rates in their offer-acceptance decisions. In the competitive search framework, Menzio and Shi (2011) model an economy with on-the-job search, aggregate shocks, and match quality, but with risk-neutral workers. As a result, they find that the constrained efficient allocation can be decentralized. We deviate from these papers by analyzing the welfare effects of the interaction between risk aversion and directed search on equilibrium hiring and separation rates.

The paper is organized as follows. Section 2 describes the environment. Section 3 investigates the constrained efficient allocation. In Section 4, we characterize the market equilibrium and its welfare properties. The infinite horizon economy is studied in Section 5. The quantitative analysis is undertaken in Section 6. Finally, Section 7 concludes. All proofs and additional analysis are postponed to the Appendix.

\section{A two-period Economy}

The economy lasts for two periods. It is populated by a unit mass of risk-averse workers, and a large continuum of risk-neutral firms. All agents discount period-two utility at the factor $\beta$. Workers are ex-ante identical, and unemployed at the beginning of period one.

The worker's utility function is additively separable in consumption and search intensity, $v(c)-$ $\phi(s)$. The function $v$ is twice continuously differentiable, increasing and concave in consumption $c$. We assume that $v(0)=0$ and $\lim _{c \rightarrow 0} v^{\prime}(c)=\infty$. Job-seekers derive disutility $\phi(s)$ if exerting search intensity s. $\phi$ is an increasing and convex function such that $\phi(0)=0$ and $\lim _{s \rightarrow 0} \phi^{\prime}(s)=0$. 
There is asymmetry across periods for simplicity. The first period is divided into two stages, search and production. The second period is also split in two stages, separations and production. Search is a costly activity not only for workers, but also for firms. Let $k$ denote the cost firms incur by posting a vacancy. An aggregate technology described below produces bilateral meetings between workers and firms. Workers who do not meet any firm in the first period remain unemployed in the second period. Upon meeting, a match is automatically formed. Two components enter multiplicatively in the time-invariant match output: an aggregate component $y$ and a matchspecific productivity component $\pi$. We build upon Jovanovic (1979), and model match-specific productivity as an experience good. Specifically, match productivity $\pi$ is drawn upon meeting from a differentiable cdf $F$ with support $\Pi$, with $0 \in \Pi$ as a lower bound, and mean $\bar{\pi} \equiv \mathbb{E}(\pi)$, but remains unobservable in period one. Productivity $\pi$ is learned at the beginning of the second period. All unemployed workers produce $z$ units of output per period at home, where $0 \leq z<\bar{\pi} y$. If a match is terminated at the beginning of the second period, the worker becomes unemployed.

Notice that workers are job-seekers in period one, while the unemployed in period two do not search by assumption. To eliminate this asymmetry across periods and keep our two-period benchmark close to a dynamic setting where all unemployed workers are job-seekers who have been separated from their jobs at some point in time, we make the following assumption. ${ }^{6}$

Assumption 1 The government and the social planner both treat all unemployed workers equally regardless of whether they fail to find a job in period one or their match is terminated in period two.

Search. Workers and firms get together via search. Let $q(m)$ denote the ratio of applicants in search efficiency units to vacancies at location $m$. We will suppress the dependence of the ratio on the location hereafter unless necessary for readiness. Firms meet workers with probability $\eta(q)$, and workers meet firms with probability $\nu(q)$ per unit of search intensity. The Law of Large Numbers applies and, hence, $q \nu(q)=\eta(q)$. Both functions are assumed to be twice continuously differentiable. Furthermore, $\eta$ is increasing in $q$ to capture the intuition that more candidates competing for the available jobs increase the prospects of any given vacancy. Similarly, $\nu$ is a

\footnotetext{
${ }^{6}$ We further discuss this assumption in the following sections.
} 
decreasing function because more job opportunities for a worker are expected in a tighter labor market. Let $\varphi$ denote the elasticity of function $\eta$, which is assumed to be a decreasing function. To guarantee vacancy creation both in the equilibrium and the constrained efficient allocations, first, we impose the following standard limit conditions

$$
\lim _{q \rightarrow 0} \eta(q)=\lim _{q \rightarrow \infty} \nu(q)=0, \text { and } \lim _{q \rightarrow \infty} \eta(q)=\lim _{q \rightarrow 0} \nu(q)=1
$$

and, second, we assume that the expected discounted output produced at the market net of the vacancy-creation costs exceeds home productivity,

$$
(1+\beta)(\bar{\pi} y-z)>k
$$

\section{The Planner's Allocation}

In this section we analyze the social planner's allocation. The social planner dictates workers what to do and chooses the mass of vacancies and consumption streams in order to maximize the expected discounted utility of a representative worker. Since workers are ex-ante identical and firms have access to the same production technology, the planner sends all workers to the same location.

The planner's problem is subject to a number of constraints. First, it cannot directly assign workers to vacancies, but it is constrained by the meeting technology described above. Second, it cannot learn match productivity in period one. It observes it at the beginning of the second period, and decides whether to terminate the match or not. Because of the monotonicity of output in the match-specific productivity, the planner sets a reservation value $R$. Third, in line with Assumption 1, the planner delivers consumption $c_{u}$ to all unemployed workers regardless of whether they fail to find a job in period one or fall into unemployment in period two. ${ }^{7}$ Fourth, the worker's search intensity is unobservable to the planner, who recommends an incentive compatible search intensity. Consistent with this recommendation, the planner commits to a consumption bundle: workers are

\footnotetext{
${ }^{7}$ Notice that if the planner were allowed to treat these two types of unemployed workers differently, it would be optimal to provide the same consumption level to the employed workers and to those whose match is terminated at the beginning of the second period due to consumption-smoothing reasons and because no incentives would be affected. This case is indeed analyzed in Appendix 8.3.
} 
promised consumption $c_{u}$ if unemployed in either period, $c_{1}$ if employed in the first period, and $c_{2}(\pi)$ if employed in the second period with match productivity $\pi$. We say that an allocation is incentive compatible if the following condition, which equates the marginal cost with the marginal benefit of search intensity, holds.

$$
\phi^{\prime}(s)=\nu(q)\left(v\left(c_{1}\right)-v\left(c_{u}\right)+\beta \int_{R}\left(v\left(c_{2}(\pi)\right)-v\left(c_{u}\right)\right) d F(\pi)\right)
$$

Fifth, the planner's allocation must be feasible. That is, the following intertemporal resource constraint must also hold. This constraint ensures that total consumption promised to unemployed and employed workers does not exceed the total output produced in the economy net of vacancy creation costs, which is the term on the right hand side.

$(3)((1-s \nu(q))(1+\beta)+s \nu(q) \beta F(R))\left(z-c_{u}\right)+s \nu(q)\left(\bar{\pi} y-c_{1}+\beta \int_{R}\left(\pi y-c_{2}(\pi)\right) d F(\pi)\right) \geq \frac{k s}{q}$

Therefore, the planner's allocation is a solution to the following program:

(4) $\max _{\substack{s, q, R, c_{u} \\ c_{1}, c_{2}(\cdot)}}\left\{-\phi(s)+s \nu(q)\left(v\left(c_{1}\right)-v\left(c_{u}\right)+\beta \int_{R}\left(v\left(c_{2}(\pi)\right)-v\left(c_{u}\right)\right) d F(\pi)\right)+v\left(c_{u}\right)(1+\beta)\right\}$ s. to conditions (2) and (3)

The following proposition establishes existence of the planner's solution, and characterizes it. ${ }^{8}$

Proposition 3.1 There exists a constrained efficient allocation $\left(s^{p}, q^{p}, R^{p}, c_{u}^{p}, c_{1}^{p}, c_{2}^{p}(\cdot)\right)$. The consumption levels are such that $z<c_{u}^{p}<c^{p}=c_{1}^{p}=c_{2}^{p}(\pi)$ for all $\pi$. In addition to constraints (2) and (3), the allocation satisfies

(5) $\eta(q)(1-\varphi(q))\left(\frac{v(c)-v\left(c_{u}\right)}{v^{\prime}(c)}+c_{u}-z+y \frac{\bar{\pi}+\beta(1-F(R)) \mathbb{E}(\pi \mid R)}{1+\beta(1-F(R))}-c\right)=\frac{k}{1+\beta(1-F(R))}$

$$
\frac{v(c)-v\left(c_{u}\right)}{v^{\prime}(c)}+c_{u}-z+R y-c \geq 0, \text { and } R \geq 0, \text { with complementary slackness }
$$

\footnotetext{
${ }^{8}$ To save on notation, we denote the conditional expected productivity as

$$
\mathbb{E}(\pi \mid R) \equiv \int_{R} \pi \frac{d F(\pi)}{1-F(R)}
$$
}


Furthermore, $R^{p} y<z$.

There is a tension between the consumption smoothing goal due to workers' risk aversion and providing the right search incentives (formally set by the incentive compatibility condition). The planner optimizes this trade-off by committing to a consumption difference between employed and unemployed workers consistent with incentive compatibility, and setting the consumption of the unemployed above home production. Besides, the constrained efficient allocation ensures perfect consumption smoothing within an employment spell. In particular, the consumption of the employed does not depend on their match-specific productivity in the second period.

Equation (6) is the first order necessary condition with respect to the reservation value, and, thus, refers to the match-termination margin. The left hand side of the inequality in expression (6) can be interpreted as the joint net value of a match conditional on the match-specific productivity being equal to $\pi$. The first term is the worker's utility difference between employment and unemployment adjusted by the marginal utility of consumption. The remaining terms amount to the net difference of output and consumption promises between employment and unemployment, $\pi y-c$ and $z-c_{u}$, respectively. This planner's condition says that it is optimal to terminate a match if and only if its net value is negative. We will refer to this as the internal efficiency condition later on.

The planner sets a reservation value such that pairs with match-specific productivity $R^{p}$ are less productive at the market than workers would be at home, i.e. $R^{p}<\hat{R} \equiv \frac{z}{y}$. This result, which follows directly from condition (6), is not intuitive as one would expect that matches would be terminated if their market output didn't exceed what they can produce separately. This would be exactly the efficiency condition if workers were risk neutral. Put differently, total output is maximized at the reservation value $\hat{R}$. With risk-averse workers instead, the planner sets the reservation value $R^{p}$ so that the net value of the match is zero, weighting the utility gains and output costs of keeping workers employed instead of sending them to unemployment. The following thought experiment helps to understand the result $R^{p}<\hat{R}$. If a risk-averse worker drew matchspecific productivity $\hat{R}-\epsilon$, with $\epsilon$ arbitrarily small, then the output costs of keeping her employed would amount to $\beta \epsilon y$, whereas the utility gains would be discrete because $c^{p}>c_{u}^{p}$. As a result, the planner sets a reservation value such that $R^{p} y<z$, and, hence, the marginal employed worker is 
more productive at home than at the market in the second period. Therefore, the efficient worker turnover is lower than the one that would be obtained if the planner maximized output.

Finally, after some manipulations, equation (5) is obtained from the first order necessary condition with respect to the queue length; hence, it refers to the match formation margin. It equates the share $1-\varphi\left(q^{p}\right)$ of the expected discounted joint net value of a match, which is formed with probability $\eta\left(q^{p}\right)$, with the vacancy creation costs. Recall that $\varphi\left(q^{p}\right)$ stands for the elasticity of the job-filling probability.

\section{Market Economy}

In this section, we first describe the additional details of the environment in the market economy. Then, we determine the equilibrium allocation and its welfare properties.

Because the ultimate goal is to examine whether or not the planner's allocation is an equilibrium outcome, we focus on internally efficient equilibria to ensure efficient separations. Later in this section, we discuss how internal efficiency can be obtained in equilibrium. Furthermore, we restrict the contracting space so that firms can only make payments in exchange for output. Although this is necessary for all unemployed workers to be treated identically in accordance with Assumption 1, this restriction clearly reduces the ability of private markets to insure away the future consumption risks. We discuss alternative settings in Section 4.5.

\subsection{Environment}

There is free entry of firms, and potentially infinitely many submarkets, identified by job offers. Each firm holds a single vacancy. Firms choose a submarket where to locate their vacancy, and workers direct their search to one submarket to maximize their expected utility. Firms compete for workers by committing to a two-tier wage schedule $x=\left(w_{1}, w_{2}\right)$, which specifies the wage to be paid in each period conditional on employment. ${ }^{9}$ Let $X \equiv[z, y]^{2}$ denote the space of contractual offers. There is perfect information about job offers. Search is directed in the sense that agents anticipate

\footnotetext{
${ }^{9}$ For expositional simplicity, and without loss of generality, we assume that wage promises cannot be contingent on match-specific productivity. Although the algebra for the characterization of the optimal match-termination policy would be more cumbersome if productivity-contingent wages were allowed, it can be shown that workers would be paid a constant wage in equilibrium irrespective of the match-specific productivity because of risk aversion.
} 
that submarkets promising a lower expected discounted employment value will be tighter. Let $q(x)$ denote the expected number of applicants in search efficiency units per vacancy at submarket $x$. As before, we will omit the contractual reference in this ratio unless necessary for clarity.

Match Termination. We focus on equilibria in which a match is terminated if and only if the joint net value of the worker-firm pair is negative. We now formalize this internal efficiency condition. Conditional on wage $w$, the joint net value of the pair as a function of productivity $\pi$ amounts to

$$
\mathcal{S}_{w}(\pi) \equiv \frac{v(w)-v(z)}{v^{\prime}(w)}+\pi y-w
$$

The joint net value is the sum of firm's profits and worker's utility if employed net of her utility if unemployed adjusted by the marginal utility of wages. $\mathcal{S}_{w}(\pi)$ can be seen as the surplus to be split between the firm and the worker. Notice that, for a given $\pi, \mathcal{S}_{w}(\pi)$ is increasing in the wage $w$. Similarly, for a given $w$, it is an increasing function of $\pi$. Therefore, the optimal decision regarding match dissolution has the reservation value property: a match is terminated if and only if $\pi$ is below the threshold $R_{w}$, where

$$
R_{w}= \begin{cases}0 & , \text { if } \mathcal{S}_{w}(0)>0 \\ \pi & , \text { such that } \mathcal{S}_{w}(\pi)=0, \text { o.w. }\end{cases}
$$

We refer to an equilibrium in which this match-termination condition holds as an internally efficient equilibrium. Notice that this expression coincides with the planner's condition (6) whenever $c_{u}^{p}=z$, as it must be the case in the laissez-faire economy. An important feature related to internal efficiency to which we will come back later is the negative relationship between $R_{w}$ and $w$ :

$$
\frac{d R_{w}}{d w}=\frac{v^{\prime \prime}(w)}{v^{\prime}(w)} \frac{v(w)-v(z)}{v^{\prime}(w)}<0, \text { if } R_{w}>0
$$

Value Functions. A firm posts a vacancy in submarket $x$ at cost $k$ if it expects to obtain nonnegative profits. A vacancy is filled with probability $\eta(q(x))$, and remains filled in the second 
period if match-specific productivity is above the threshold. The firm's value is

$$
V=-k+\max _{x} \eta(q(x))\left(\bar{\pi} y-w_{1}+\beta \int_{R_{w_{2}}}\left(\pi y-w_{2}\right) d F(\pi)\right)
$$

Free entry implies that the expected returns from posting a vacancy must be zero, $V=0$.

Workers decide which submarket $x$ to search for a job and the search intensity $s$. They become employed with probability $s \nu(q(x))$, and remain employed in the second period with probability $1-F\left(R_{w_{2}}\right)$. If employed, workers derive utility from the wages stipulated in the contract. Otherwise, they enjoy their home production. Job-seekers search in submarket $x$ if it maximizes the expected discounted value of doing so. That is, the following condition must hold for any submarket $x \in X$,

$$
U \geq \max _{s}\left\{-\phi(s)+s \nu(q(x))\left(v\left(w_{1}\right)-v(z)+\beta \int_{R_{w_{2}}}\left(v\left(w_{2}\right)-v(z)\right) d F(\pi)\right)\right\}+v(z)(1+\beta),
$$

$$
\text { and } q(x) \geq 0 \text {, with complementary slackness }
$$

\subsection{Equilibrium}

Next, we define the internally efficient competitive search equilibrium.

Definition 1 An internally efficient competitive search equilibrium consists of an unemployment value $U$, a search intensity function $\hat{s}: X \rightarrow[0,1]$, a queue length function $Q: X \rightarrow \mathbb{R}_{+} \cup\{\infty\}$, a contract $x \in X$, and a match-termination policy such that

i) Internal efficiency:

For any $\pi \in \Pi$ and $x^{\prime} \in X$, a match is dissolved if its specific productivity $\pi$ is below the reservation value $R_{w_{2}^{\prime}}$, which is determined by condition (7).

ii) Firm's profit maximization and zero-profit condition:

For any $x^{\prime} \in X$,

$$
\eta\left(Q\left(x^{\prime}\right)\right)\left(\bar{\pi} y-w_{1}^{\prime}+\beta \int_{R_{w_{2}^{\prime}}}\left(\pi y-w_{2}^{\prime}\right) d F(\pi)\right) \leq k
$$

and this holds with equality at $x$. 
iii) Worker's optimal search:

For any $x^{\prime}, Q\left(x^{\prime}\right)$ and $\hat{s}\left(w^{\prime}\right)$ satisfy condition (9). In particular, for the equilibrium contract $x$,

$$
U=-\phi(\hat{s}(x))+\hat{s}(x) \nu(Q(x))\left(v\left(w_{1}\right)-v(z)+\beta \int_{R_{w_{2}}}\left(v\left(w_{2}\right)-v(z)\right) d F(\pi)\right)+v(z)(1+\beta)
$$

The above definition establishes that the optimal policy that rules match dissolution has the reservation value property. According to the second condition, firms choose the profit-maximizing contract, and free entry implies that expected discounted profits are zero in equilibrium. The third condition ensures that workers enter a submarket if the contract maximizes their expected utility. This equilibrium condition also pins down the off-the-equilibrium expectations about the queue length at any submarket, thereby helping agents make their optimal decisions on the equilibrium path.

The following proposition establishes existence of the equilibrium allocation, and characterizes it.

Proposition 4.1 An internally efficient competitive search equilibrium solves the following program, and, conversely, a solution of the program takes part of an equilibrium allocation.

$$
\begin{aligned}
\max _{s, q, w_{1}, w_{2}} & \left\{-\phi(s)+s \nu(q)\left(v\left(w_{1}\right)-v(z)+\beta \int_{R}\left(v\left(w_{2}\right)-v(z)\right) d F(\pi)\right)\right\} \\
\text { s. to } & \eta(q)\left(\bar{\pi} y-w_{1}+\beta \int_{R}\left(\pi y-w_{2}\right) d F(\pi)\right) \geq k, \text { and condition }(7)
\end{aligned}
$$

There exists an equilibrium allocation. It is determined by the zero-profit condition, the optimal match-termination condition (7), and

$$
\begin{aligned}
w_{1} & =w_{2}=w \\
\phi^{\prime}(s) & =\nu(q)\left(v(w)-v(z)+\beta \int_{R}(v(w)-v(z)) d F(\pi)\right) \\
\frac{k}{1+\beta(1-F(R))} & =\eta(q)(1-\varphi(q))\left(\frac{v(w)-v(z)}{v^{\prime}(w)}+y \frac{\bar{\pi}+\beta(1-F(R)) \mathbb{E}(\pi \mid R))}{1+\beta(1-F(R))}-w\right)
\end{aligned}
$$


Furthermore, in equilibrium, $R y<z<w$.

A tuple $\left(s, q, R, w_{1}, w_{2}\right)$ takes part of an equilibrium allocation if and only if it maximizes the worker's expected discounted utility subject to firms obtaining nonnegative expected discounted profits and the match-termination condition. The equilibrium conditions (12) and (13) are the first order conditions of program (10) with respect to search intensity $s$ and queue length $q$, respectively. The former equates the marginal disutility of a unit of search intensity with its marginal utility gains, which amount to the net value of employment times the job-finding probability. The latter equation in turn equates the marginal cost of creating a vacancy $k$ with the marginal expected discounted profits, which are the probability of filling the vacancy $\eta(q)$ times the share $1-\varphi(q)$ of the following expression,

$$
\left.\left(\frac{v(w)-v(z)}{v^{\prime}(w)}-w\right)(1+\beta(1-F(R)))+y(\bar{\pi}+\beta(1-F(R)) \mathbb{E}(\pi \mid R))\right)
$$

This expression resembles the joint net value of the match conditional on productivity $\pi, \mathcal{S}_{w}(\pi)$. The difference only stems from the point in time in which the match value is assessed, with this expression being the joint net value at the meeting time. Notice that if workers were risk neutral instead, the joint value of the match would amount to market production net of home productivity.

As in the implicit contract literature, firms behave as employers and insurers of their riskaverse workers in equilibrium because of the different ability of firms and workers to bear risk. This is reflected in both the match-dissolution decision and time-invariant wages (constant in matchspecific productivity) as equilibrium equation (11) expresses. Regarding the match-termination policy, consider the case in which the reservation value $R$ is strictly positive, and, hence, the internal efficiency condition (7) can be rewritten as

$$
\frac{v(w)-v(z)}{v^{\prime}(w)}+R y-w=0
$$

The left hand side of this expression amounts to the adjusted joint net value of the job-worker pair with match-specific productivity $R, \mathcal{S}_{w}(R)$. If workers were risk neutral, the threshold $R$ would be such that market productivity equalized home productivity, $R y=z$. Under risk aversion, worker's 
productivity is lower at the market than at home. This is internally efficient because the utility gains of the worker outweigh the negative profits of the firm. Notice that the first term is positive since it accounts for the worker's adjusted utility in excess of what she derives from home production. Therefore, firms make negative profits in equilibrium when match-specific productivity falls in a neighborhood of the threshold. We turn now to provide insight into why firms do not post lower wages to obtain higher profits. In a nutshell, lower wages would increase the match-termination probability, which would not be attractive to risk-averse job-seekers.

Trading off unemployment risks intertemporally. Recall that $\frac{d R_{w}}{d w}<0$. Intuitively, the continuation of a match with a low wage requires a high match-specific productivity. This negative relationship points to the trade-off that the internal efficiency condition (14) poses between present and future unemployment risks in equilibrium. To be more concrete, Proposition 4.1 states that equilibrium wages are time-invariant because of workers' risk aversion. Furthermore, risk-averse workers apply to low-wage jobs to increase the employment likelihood in period one. However, lower wages reduce the joint value of the match $\mathcal{S}_{w}(\pi)$, for any given $\pi$; thereby increasing the match-specific threshold and also, separation rates.

Importantly, notice that this trade-off also depends on the consumption enjoyed if unemployed. Put differently, policies that target the lack of insurance against unemployment risks also affect such a trade-off and, hence, worker turnover. We shall come back to this point later in this section.

Can internal efficiency be obtained endogenously in equilibrium? In our benchmark, firms commit to two-wage contracts in the search stage. If the match-termination decision were made to maximize profits after learning the match-specific productivity instead, the reservation value would be $R=w_{2} / y$. Similarly, if the contracting space were restricted to self-enforcing two-wage contracts to ensure that walking away from the contract would never be profitable, the reservation value would also be $R=w_{2} / y$. In either case, the equilibrium allocation would not be internally efficient (hence, nor constrained efficient) as a number of matches with positive joint net value would be terminated.

Internal efficiency refers to the resolution of the coordination problem that takes place within the match to ensure its continuation if jointly desirable. We now briefly sketch alternative environments 
in which internal efficiency is obtained endogenously in the market economy through either more complete contracting environments or an efficient negotiation process within the match.

Consider first a wider contracting space in which firms commit to a reservation match-specific productivity in addition to wages, so $x=\left(w_{1}, w_{2}, R\right)$. The equilibrium allocation is the solution of problem (10) without constraint (7), and now with $R$ as a control variable. The optimal threshold $R$ turns out to satisfy the internal efficiency condition (7). Therefore, if firms can commit to longterm contracts that establish explicit separation rates, the equilibrium allocation coincides with the internally efficient equilibrium one. To have some understanding of why the profit-maximizing cutoff ensures internally efficient separations, let us write the firm's problem as

$$
\begin{array}{cc}
\max _{q,\left(w_{1}, w_{2}, R\right)} & \eta(q)\left(\bar{\pi} y-w_{1}+\beta \int_{R}\left(\pi y-w_{2}\right) d F(\pi)\right) \\
\text { s. to } & \max _{s}\left\{v(z)(1+\beta)-\phi(s)+s \nu(q)\left(v\left(w_{1}\right)-v(z)+\beta \int_{R}\left(v\left(w_{2}\right)-v(z)\right) d F(\pi)\right)\right\} \geq U
\end{array}
$$

The firm sets the profit-maximizing contract rationally anticipating the associated queue lengths to any possible offer. The first order conditions with respect to variables $R$ and $w_{2}$ are, respectively,

$$
\begin{gathered}
R y-w_{2}+\frac{\xi s}{q}\left(v\left(w_{2}\right)-v(z)\right) \geq 0, \quad \text { and } \quad R \geq 0, \text { with complementary slackness, } \\
-1+\frac{\xi s}{q} v^{\prime}\left(w_{2}\right)=0
\end{gathered}
$$

where $\xi$ is the Lagrange multiplier. In words, the profit-maximizing decisions regarding $R$ and $w_{2}$ combine the period-two firm's profits and the period-two net utility of the employee indirectly through the competition for job-seekers. Interestingly, the worker's utility is adjusted by the same factor in both cases. From the second equation, we obtain that the adjusting term must be equal to the reciprocal of the marginal utility of wage $w_{2}$. As a result, the first necessary condition coincides with the internal efficiency condition (7).

More generally, notice that settings in which separations take place even if the joint value of the match is positive are particularly restrictive as they rule out any sort of ex-post agreements that are mutually desirable. For example, consider a more flexible setting in which firms commit to a two-wage schedule, and decide unilaterally whether to terminate a match or not after learning 
the match-specific productivity, but period-two wages can be renegotiated if mutually beneficial. Then, in case that period-two profits were negative because of too low a match-specific productivity, voluntary wage cuts could make firms break-even while keeping the joint value positive. We also argue in Section 4.5.2 that internal efficiency is obtained if firms commit to period-one wages, while period-two wages are bargained over after learning the match-specific productivity.

Comparative Statics. Next, we perform two comparative static exercises with respect to some fundamentals. Lemma 4.2 can be read as an extension of Proposition 2 in Acemoglu and Shimer (1999) to our setting. We obtain that the more risk-averse workers are and the smaller their home production is, the larger the measure of jobs created in the economy is and the lower the wages and the threshold are in order to provide more insurance against unemployment risks in both periods. Notice that, as pointed out above, the trade-off between present and future unemployment risks differs across these economies.

Lemma 4.2 Let $\left(w_{i}, q_{i}, R_{i}, s_{i}\right)$ denote the equilibrium tuple of the economy indexed by $i \in\{A, B\}$. If two economies differ in

1. the workers' utility function $v$, and $v_{B}$ is a concave monotonic transformation of $v_{A}$, then $w_{B}<w_{A}, q_{B}<q_{A}$, and $R_{B}<R_{A}$ (unless $R_{B}=R_{A}=0$ ).

2. the home production value, and $z_{B}<z_{A}$, then $w_{B} \leq w_{A}, q_{B} \leq q_{A}$, and $R_{B} \leq R_{A}$, with all strict inequalities if $R_{B}>0$.

Furthermore, if two economies differ in the cumulative distribution function $F$, agents benefit from the better technology in producing more productive matches, which leads not only to more vacancies and higher job-finding rates and wages, but also to lower match-termination rates because of the negative relationship between wages and the productivity threshold that internal efficiency implies. We have postponed the details to the Online Appendix.

\subsection{Welfare Properties of the Equilibrium Allocation}

It is apparent from Propositions 3.1 and 4.1 that the internally efficient equilibrium is not constrained efficient because the equilibrium consumption of the unemployed falls short of the efficient 
level. In addition, Proposition 4.3 states that the equilibrium job-finding and job-termination rates are higher and lower than their planner's counterparts, respectively.

Proposition 4.3 The internally efficient competitive search equilibrium is not constrained efficient. Furthermore, if $R^{p}>0$, then the equilibrium threshold and queue length are lower than their constrained efficient counterparts, whereas the search intensity is larger. Thus, the job-finding rate is inefficiently high, and the job-termination rate and output per worker are inefficiently low.

To understand this inefficiency result, let us first note that the internally efficient equilibrium is constrained efficient if either workers are risk neutral or the planner is not allowed to promise unemployed workers a consumption level different from $z \cdot{ }^{10}$ This result is not surprising since, as shown in Moen (1997), constrained efficiency can be attained in the baseline competitive search model because wages efficiently price waiting time, and the additional margin introduced in our setting regarding match-dissolution decisions is efficiently set in the internally efficient equilibrium. Therefore, we must conclude that the inefficiency in the laissez-faire economy is due to the suboptimally insured unemployment (i.e. consumption) risks. This inefficiency relies on market incompleteness of various forms. First, workers can neither save nor sign contracts with third parties to insure themselves against negative search outcomes. ${ }^{11}$ Second, and unlike Jacquet and Tan (2012), workers and firms cannot trade applications, but labor. More precisely, firms can only reward successful applicants while employed. These missing markets prevent the consumption of unemployed workers from exceeding their home production in the laissez-faire economy. Against these consumption risks, markets have two margins to offer a sort of insurance: a job-creation (or match-formation) margin and a match-destruction margin. The first margin refers to period-one risks, and, hence, to the planner and equilibrium equations (5) and (13), respectively; whereas the second margin refers to period-two risks, and, thus, to equations (6) and (14). These two margins are used inefficiently in the market economy: the equilibrium queue length and reservation match-specific productivity are both too low in equilibrium.

\footnotetext{
${ }^{10}$ Formally, this is because the planner condition regarding the queue length (5) and the internal efficiency condition (6) are exactly the same as their equilibrium counterparts (13) and (7), respectively, except for the difference $c_{u}-z$, and this consumption gap between the planner's and the equilibrium allocations is eliminated in either of these two alternative settings.

${ }^{11} \mathrm{As}$ in Golosov et al. (2013), it can be proved that if an insurance market operated for workers to insure away unemployment risks, the equilibrium allocation would be constrained efficient.
} 
This translates into macroeconomic aggregates. First, the equilibrium unemployment rate is lower than its planner's counterpart: the unemployment rate in period two amounts to $1-s \nu(q)(1-$ $F(R)$ ), which is increasing in $q$ and $R$ and decreasing in $s$. Second, hiring rates are inefficiently high, while separation rates (over total employment) are too low. Thus, it is unclear whether the equilibrium worker turnover rate, defined as the sum of the hiring plus the separation rates, is inefficiently high or not. Likewise, the comparison regarding total output in the second period is also ambiguous because, although employment is larger in equilibrium, average match productivity is lower.

\subsection{Implementation}

Next, we state that the planner's allocation can be implemented in the market economy. Our main theoretical contribution is that match-formation and -continuation must be subsidized and layoff taxes must be zero.

Policy. Incomplete markets call for public provision of insurance against unemployment risks. We allow for three different types of taxes to finance such an insurance scheme. Consider a policy that comprises unemployment benefits $b$, a lump sum tax $T$, a proportional income tax rate $\tau$, and a layoff tax $L .^{12}$ Notice that taxes affecting worker's labor income alter their search behavior, and layoff taxes distort match-termination decisions. The government's intertemporal balanced budget constraint is

$(15) b((1-s \nu(q))(1+\beta)+\beta s \nu(q) F(R))=T(1+\beta)+\tau w s \nu(q)(1+\beta(1-F(R)))+L \beta s \nu(q) F(R)$

The cost of the public insurance is shown on the left hand side. The tax revenue is on the right hand side, and comprises revenue from the lump sum tax, income taxes paid by employed workers and the layoff tax paid by firms when a match is terminated.

\footnotetext{
${ }^{12}$ Following the literature, we consider UI benefits as lump sum transfers instead of proportional to past wages. As we will see in this section, lump sum transfers -together with the other fiscal instruments- suffices to implement the planner's allocation in the market economy. However, in this context, if UI were modeled as a replacement rate, firms would provide insurance against future consumption risks by offering higher wages. This would pose a new intertemporal trade-off related to expected-profit-maximizing wages.
} 


\section{Tax-distorted Equilibrium.}

Definition 2 Given policy $(G, b, T, \tau, L)$, a tax-distorted internally efficient competitive search equilibrium consists of an unemployment value $U$, a search intensity function $\hat{s}: X \rightarrow[0,1], a$ queue length function $Q: X \rightarrow \mathbb{R}_{+} \cup\{\infty\}$, a contract $x \in X$, and a match-termination policy such that

i) Internal efficiency:

For any $\pi \in \Pi$ and $x^{\prime} \in X$, a match is dissolved if its specific productivity $\pi$ is below the reservation value $R_{w_{2}^{\prime}}$, which is determined by the following equation

$$
\frac{v^{\prime}\left(w_{2}^{\prime}(1-\tau)-T\right)-v^{\prime}(z+b-T)}{v^{\prime}\left(w_{2}^{\prime}(1-\tau)-T\right)(1-\tau)}+R y-w_{2}^{\prime}=-L, \text { if } R>0, \text { and } 0 \text { o.w. }
$$

ii) Firm's profit maximization and zero-profit condition:

For any $x^{\prime} \in X$,

$$
\eta\left(Q\left(x^{\prime}\right)\right)\left(\bar{\pi} y-w_{1}^{\prime}+\beta \int_{R_{w_{2}^{\prime}}}\left(\pi y-w_{2}^{\prime}\right) d F(\pi)-\beta F(R) L\right) \leq k
$$

and this holds with equality at $x$.

iii) Worker's optimal search:

For any $x^{\prime}, Q\left(x^{\prime}\right)$ and $\hat{s}\left(w^{\prime}\right)$ make the policy-adjusted counterpart of condition (9) hold. In particular,

$$
\begin{aligned}
U= & -\phi(\hat{s}(x))+\hat{s}(x) \nu(Q(x))\left(v\left(w_{1}(1-\tau)-T\right)-v(z+b-T)+\right. \\
& \left.\beta \int_{R_{w_{2}}}\left(v\left(w_{2}(1-\tau)-T\right)-v(z+b-T)\right) d F(\pi)\right)+v(z+b-T)(1+\beta)
\end{aligned}
$$

iv) The government balanced budget constraint (15) holds.

To avoid repetition, since the equilibrium definition only differs from Definition 1 in the fiscal instruments and the government constraint, we just comment on these new items. Regarding the 
internal efficiency condition (16), income taxes reduce the joint value of the match, whereas the layoff tax appears with a negative sign on the right hand side as it becomes a burden in case of match dissolution. Likewise, the expected discounted profits from any contract $x^{\prime}$ in expression (17) also take into account the layoff tax if the match is terminated. The last equilibrium condition ensures that the government's revenue equals its spending intertemporarily.

To characterize the equilibrium allocation under policy $(G, b, T, \tau, L)$, let us write the counterpart of program (10) as ${ }^{13}$

$$
\begin{aligned}
(18) \max _{w, R, q, s} & \left\{-\phi(s)+s \nu(q)\left(v(w(1-\tau)-T)-v\left(c_{u}\right)+\beta \int_{R}\left(v(w(1-\tau)-T)-v\left(c_{u}\right)\right) d F(\pi)\right)\right\} \\
\text { s. to } & \eta(q)\left(\bar{\pi} y-w+\beta \int_{R}(\pi y-w) d F(\pi)-\beta F(R) L\right) \geq k
\end{aligned}
$$

where $c_{u}=z+b-T$. The first order condition with respect to vacancy creation, and hence the counterpart of condition (13), is, after some manipulations,

$$
\eta(q)(1-\varphi(q))((\bar{\pi}-R+\beta(1-F(R))(\mathbb{E}(\pi \mid R)-R)) y-L(1+\beta))=k
$$

This equation together with the first order condition with respect to search intensity, the zeroprofit condition, the internal efficiency condition (16) and the government budget constraint (15) characterize the equilibrium allocation.

Decentralization of the Planner's Allocation. The following proposition states that the constrained efficient allocation can be decentralized if an unemployment insurance system is financed by a lump sum tax. Furthermore, a negative income tax must be levied, while layoff taxes must be zero.

Proposition 4.4 Consider $R^{p}>0$. Constrained efficiency is attained in the market economy if a government sets an unemployment insurance system funded through lump sum and negative proportional income taxes, whereas layoff taxes must be zero.

\footnotetext{
${ }^{13}$ For notational reasons, we have imposed the equilibrium result of $w_{1}=w_{2}=w$, and, taking advantage of previous results that show the redundancy of the internal efficiency condition, we have removed it.
} 
To see this, rewrite the planner's condition (5), using condition (6), as

$$
\eta(q)(1-\varphi(q))(\bar{\pi}-R+\beta(1-F(R))(\mathbb{E}(\pi \mid R)-R)) y=k
$$

This equation coincides with the tax-distorted equilibrium condition (19) if and only if no layoff taxes are levied, $L=0$. Likewise, the planner's and equilibrium conditions (6) and (16), respectively, coincide with one another if and only if the following equality holds

$$
\tau R^{p} y=-b
$$

This result is intuitive. In the laissez-faire equilibrium, internal efficiency implies that firms make negative profits ex-post if the match-specific productivity is within a neighborhood of the threshold $R .{ }^{14}$ Recall that this is due to the sort of insurance that firms offer in the labor market when competing for risk-averse workers. If a government partly insures away the consumption risks by making transfers to the unemployed, it crowds out the private insurance firms offer in the laissezfaire equilibrium; thereby inducing firms to increase the reservation productivity (and wages). Jobseekers are now riskier in their search strategies because of the publicly-provided insurance. The reservation value turns out to be inefficiently high. Then, implementing the constrained efficient threshold requires subsidies to cover the potential losses firms will face when lowering the threshold. Although firms could be subsidized in several different forms, the efficient way to distort agent's attitudes in the competitive search framework is through the contractual offers. Therefore, layoff taxes must be zero because they not only distort the match-termination decision, but also job creation in a nonefficient way, whereas a negative income tax provides the proper search incentives to firms and workers. Expression (21) specifies that the subsidy firms receive is proportional to unemployment benefits, $\tau w=-b \frac{w}{R^{p} y}$.

This result sharply contrasts with Blanchard and Tirole (2008), who highlight the importance of coordination frictions in the labor market. In order to decentralize the planner's allocation in their frictionless economy, income taxes must be zero and layoff taxes must be equal to unemploy-

\footnotetext{
${ }^{14}$ The expected profits derived from a filled vacancy are hump-shaped as a function of $R$, reaching the peak when $R y=w_{2}$.
} 
ment benefits. This Pigovian tax makes firms internalize the social costs of match termination. Furthermore, they conjecture that layoff taxes should exceed unemployment benefits when search incentives are present in order to discourage layoffs because the employment value outweighs the unemployment one.

\subsection{Discussion}

In this section, we examine some central assumptions.

\subsubsection{On Match Quality and the Intertemporal Trade-off.}

We have modeled match-specific productivity as an experience good, which leads to a trade-off between present and future unemployment risks. This trade-off can be modeled in alternative ways. In the Online Appendix, we follow Pries and Rogerson (2005) and consider an economy where match quality is both an inspection good and an experience good. In such a setting, the match quality threshold affects both present and future employment probabilities in opposite directions by construction: a lower reservation value makes period-one meetings more likely to become matches, but those matches are more fragile as the period-two expected productivity is lower. The key results derived in our benchmark economy are robust and extend to this alternative model. Nonetheless, as match quality is also an inspection good, UI benefits also have a search-subsidy feature à la Burdett (1979).

\subsubsection{Bargained Wages.}

We now briefly examine the case in which firms have a limited long-term commitment power. Consider an economy wherein firms commit to a wage for the first period and period-two wages are Nash-bargained after learning the specific productivity. Consider for simplicity symmetric information regarding match productivity between the worker and the firm. In this setting, the

firm and the worker bargain to split the surplus, which amounts to $\frac{v\left(w_{2}\right)-v(z)}{v^{\prime}\left(w_{2}\right)}+\pi y-w_{2}$; thereby, internal efficiency is obtained in equilibrium. However, unlike in the benchmark where equilibrium wages are time-invariant, in this setting there is no trade-off between present and future risks because match-termination decisions are not determined by job-creation decisions, i.e. there is no 
link between period-one wages and the termination decision in period two.

If workers were risk neutral, the surplus would be $\pi y-z$ and the equilibrium allocation would be constrained efficient regardless of the bargaining power of the worker as both job-creation and match-termination decisions would be efficiently set. However, under risk aversion, the laissezfaire equilibrium is not constrained efficient because of (1) the worker's inability of insuring away unemployment risks, and (2) the lack of markets for workers to insure away the consumption risks within an employment spell as bargained wages are increasing in match-specific productivity. Our conjecture is that the planner's solution cannot be implemented in this economy because income taxes would play two roles: to subsidize firms and to equalize consumption among employed workers between and within periods.

\subsubsection{Precautionary Savings}

In the competitive search literature, the analysis of the risks workers face in the labor market has been mostly restricted to economies in which risk-averse workers cannot self-insure through savings. ${ }^{15}$ This is for tractability reasons because workers with different asset holdings search for different combinations of unemployment risk and employment values. See e.g. Golosov et al. (2013), Lamadon (2014) and Rudanko (2009). ${ }^{16}$

In line with this literature, our analysis restricts itself to the case in which workers cannot insure themselves through precautionary savings. In Appendix 8.3 instead, we analyze an extended version of the model in which workers can use savings to smooth consumption over time, but are borrowing-constrained. In this setting, firms fully frontload wages because they internalize the worker's ability to transfer resources from period one to period two when designing the profitmaximizing contract. As a result, workers employed in period one achieve constant consumption across periods regardless of their employment status in period two, and the productivity threshold is $R=z / y$. Unlike period-two risks, and as in our benchmark economy, period-one unemployment

\footnotetext{
${ }^{15}$ Chetty (2008) finds that the typical unemployed worker is quite liquidity constrained, with the median household net liquid wealth being approximately 200 in 1990 dollars.

${ }^{16}$ The first show the implications for income inequality of risk-averse workers facing uninsured unemployment risks and holding no assets. The second analyzes the insurance role of long-term contracts and the transmission of firm shocks to wages and employment in an extended version of Menzio and Shi (2011) with risk-averse workers. The third explains wage rigidity in a business cycle model in which risk-neutral firms smooth workers' consumption through long-term contracts. An exception is Acemoglu and Shimer (1999), who do allow workers to save, but reduce the analysis to workers with CARA preferences to avoid the above complications.
} 
risks are still not fully insured regardless of the asset holdings workers are endowed with. Firms respond to job-seekers' preferences for securing employment by creating too many low-wage jobs in equilibrium. Furthermore, constrained efficiency is attained in a tax-distorted equilibrium with a publicly-provided unemployment insurance and a negative proportional income tax funded through lump sum taxes as in the benchmark economy with no precautionary savings. Moreover, to the extent that there exists limits to fully insure workers against future consumption risks in a dynamic economy, the trade-off between present and future risks is still present.

\subsubsection{Severance Payments}

Because of the asymmetry between the two periods, the contracting space in our setting is restricted to permit payments only to employees in exchange for labor. Therefore, privately-provided unemployment benefits and, in particular, severance payments are ruled out. ${ }^{17}$ Recall that the planner faces a similar constraint in the centralized economy studied in Section 3: laid-off workers cannot obtain a higher consumption than the level promised to those workers who fail to find a job in the first period.

In the competitive search literature, voluntary severance payments have been often discarded by focusing on equilibria with self-enforcing contracts, also referred to as limited commitment equilibria.

However, full commitment is assumed in our setting, and, as stated in Proposition 4.1, firms obtain a negative expected discounted value in a neighborhood of the match productivity threshold. How would the results change if contracts stipulate a two-wage schedule and a severance pay? Given the different ability to bear risks, firms would find it optimal to promise a constant consumption level to workers over time and regardless of their employment status in the second period. ${ }^{18}$ As a result, internally efficient match-termination decisions would imply a reservation value $R=z / y$ because there would be no utility difference between employment and unemployment in the second period. Therefore, this case resembles the economy with savings, and, to the extent that consumption risks

\footnotetext{
${ }^{17}$ We want to thank Melvyn Coles and Espen Moen for the discussion on severance payments. Also notice that severance pay, which is a voluntary agreement between employee and employer in the US, affects less than $20 \%$ of the unemployed according to Chetty (2008).

${ }^{18}$ In a dynamic setting, firms would design this private insurance to be incentive compatible because of moral hazard problems as the unemployed's search effort would not be observable to them after a match dissolution.
} 
cannot be fully insured away in a dynamic setting, there exists a trade-off between present and future risks.

\section{$5 \quad$ Infinite Horizon Model}

This section extends the previous setting to an infinite horizon economy. To avoid redundant descriptions, we first describe only the additional features of the dynamic environment, and, then, characterize the equilibrium allocation in the steady state. The main result of this section is that the policy implications derived in the two-period model carry over to the dynamic model. This dynamic model will be used in Section 6 to undertake a quantitative exercise. Because of our focus on the steady state, we will omit time subindices hereafter for notational simplicity.

\subsection{Setup}

Time is continuous. There is a mass one of infinitely-lived, risk-averse workers and free entry of risk-neutral firms. Firms and workers discount future utility at common rate $r$. The flow utility function of workers, $v(c)-\phi(s)$, satisfies the properties listed in Section 2. ${ }^{19}$ Markets are incomplete. In particular, workers cannot insure themselves against income risks through saving and borrowing, and firms can only pay their own employees in exchange for output.

Workers can be either employed or unemployed at any instant. A firm incurs cost $k$ when posting a single vacancy, and commits to a time-invariant wage offer $w \in[z, y]$. A vacancy is filled at Poisson rate $\eta(q(w))$, where $q(w)$ denotes the expected queue length at submarket defined by contract $w$. Unemployed workers choose a submarket to seek job opportunities and search intensity $s \in \mathcal{R}_{+}$. They become employed at wage $w$ at Poisson rate $s \nu(q(w))$. Let $\varphi$ denote the elasticity of function $\eta$. The properties of functions $\eta$ and $\nu$ are the same as before, except that they are now not bounded above. ${ }^{20}$

Match-specific productivity is an experience good. Productivity $\pi$ is drawn from a cdf $F$ at

\footnotetext{
${ }^{19}$ Since in this setting search intensity is unbounded $\left(s \in \mathcal{R}_{+}\right)$we assume $\lim _{s \rightarrow \infty} \phi^{\prime}(s)=\infty$.

${ }^{20}$ In particular, the limit conditions become $\lim _{q \rightarrow \infty} \eta(q)=\lim _{q \rightarrow 0} \nu(q)=\infty$.
} 
the meeting time, and is learned at Poisson rate $\alpha$ at every instant. ${ }^{21} \mathrm{~A}$ match may be hit by a destruction shock, which arrives at Poisson rate $\lambda$. To ensure that firms have incentives to create vacancies, we impose that $\frac{\bar{\pi} y-z}{r+\lambda}>k$.

Government. We consider a government that in the steady state sets an unemployment insurance system, with benefits $b$, and faces exogenous government expenditures $G$. This public spending is financed through lump sum taxes $T$, proportional income tax rates $\tau$ and layoff taxes on endogenous separations $L$. The government's budget is balanced intertemporarily; hence, let $D$ denote the steady-state level of public debt. ${ }^{22}$

Match Termination. As before, we focus on internally efficient separations. That is, a match is terminated upon learning the match-specific productivity if and only if the joint value of the match is negative. The joint value of a worker-firm pair with productivity $\pi$ and wage $w$ amounts to

$$
\mathcal{S}_{w}(\pi)=\frac{v\left(\chi_{e}\right)-r U}{v^{\prime}\left(\chi_{e}\right)(1-\tau)(r+\lambda)}+\frac{\pi y-w}{r+\lambda}+L
$$

where $\chi_{e} \equiv w(1-\tau)-T$, and $U$ stands for the unemployment value, which is defined below. The joint value of the pair is the sum of firm's expected discounted profits net of its losses $L$ in case of separating, and worker's employment value net of her utility if unemployed adjusted by the marginal utility of wages. Since $\mathcal{S}_{w}$ is an increasing function of $\pi$, a match is terminated if and only if $\pi$ is below the threshold $R_{w}$, where

$$
R_{w}= \begin{cases}0 & , \text { if } \mathcal{S}_{w}(0)>0 \\ \pi & , \text { such that } \mathcal{S}_{w}(\pi)=0, \text { o.w. }\end{cases}
$$

Consider the case of a positive threshold $R_{w}$ in the steady state allocation. As in the twoperiod economy, internal efficiency implies $\frac{d R_{w}}{d w}<0$, thereby establishing a tension between lowering

\footnotetext{
${ }^{21}$ For expositional ease, we assume that there is no inference from past noisy realizations of output.

${ }^{22}$ In search models of the labor market, it is usually assumed that firms borrow on perfect financial markets to finance the vacancy-posting costs. Consistently, the planner must be able to access such financial markets to transfer resources intertemporarily; hence, the government's budget constraint must also be balanced intertemporarily to decentralize the planner's allocation.
} 
present unemployment risks through a smaller wage $w$ and future risks because of a higher threshold $R_{w}$

Furthermore, for any given wage $w$, there is a positive relationship between the continuation value of unemployment $U$ and the threshold $R_{w}$ because a higher $U$ reduces the joint value and thus requires a higher match productivity for it to be nonnegative. In particular, employment protection policies now affect endogenous job destruction not only through its direct incentives, but also indirectly through the worker's option value of search.

Value Functions. Job-seekers derive utility from consumption and disutility from searching. Consumption amounts to home production $z$ and transfers from the Government, $\chi_{u} \equiv z+b-T$. An unemployed worker becomes employed at Poisson rate $s \nu(q(w))$ when applying to a type- $w$ job, and then obtains employment value $E(w)$. The dynamic counterpart of the equilibrium condition (9) is

$$
\begin{array}{r}
r U \geq \max _{s}\left\{v\left(\chi_{u}\right)-\phi(s)+s \nu(q(w))(E(w)-U)\right\} \\
\quad \text { and } q(w) \geq 0, \text { with complementary slackness }
\end{array}
$$

An employed worker derives utility from after-tax wages $\chi_{e}$, and is exogenously separated at rate $\lambda$. If the match-specific productivity is still unknown, it is learned at Poisson rate $\alpha$, in which case the match is terminated with probability $F\left(R_{w}\right)$. When separated, the worker obtains unemployment value $U$. The value function of employment in a match with unknown productivity $E$ satisfies the following Bellman equation.

$$
\begin{aligned}
r E(w)= & v\left(\chi_{e}\right)+\left(\lambda+\alpha F\left(R_{w}\right)\right)(U-E(w))+ \\
& \alpha\left(1-F\left(R_{w}\right)\right)\left(\frac{v\left(\chi_{e}\right)+\lambda U}{r+\lambda}-E(w)\right)
\end{aligned}
$$

A firm incurs cost $k$ when creating a vacant position, which is filled at Poisson rate $\eta(q(w))$. A match-specific productivity is drawn from cdf $F$ upon matching. The expected discounted value of 
posting a vacancy is zero because of free entry. That is,

$$
0=-k+\max _{w} \eta(q(w)) J(w)
$$

where $J$ is the (expected) value function of a filled job with unknown productivity. This amounts to the expected flow profits $\bar{\pi} y-w$ plus the continuation value if the match is not terminated because of either an exogenous shock or the match productivity turning out to be excessively low. ${ }^{23}$ In this latter case, the firm incurs the layoff tax. If match productivity is learned to be sufficiently high, the expected flow profits raise to $\mathbb{E}(\pi \mid R) y-w$.

$$
\begin{aligned}
r J(w)= & \bar{\pi} y-w-\lambda J(w)-\alpha F(R)(L+J(w))+ \\
& \alpha(1-F(R))\left(\frac{\mathbb{E}(\pi \mid R) y-w}{r+\lambda}-J(w)\right)
\end{aligned}
$$

Laws of Motion. Let $u$ and $e$ denote the rate of unemployment and the rate of employment with unknown match-specific productivity at any instant, respectively. Their laws of motion are

$$
\begin{aligned}
\dot{u} & =\lambda(1-u)+\alpha F\left(R_{w}\right) e-s \nu(q) u \\
\dot{e} & =s \nu(q) u-(\lambda+\alpha) e
\end{aligned}
$$

The increase in unemployment stems from the difference between the mass of newly unemployed workers (both from exogenous and endogenous separations) and the mass of newly employed workers. Likewise, the mass of the employed with unknown match productivity increases as a result of flows into employment from unemployment, and decreases because of both separations and learning.

\subsection{Tax-distorted Equilibrium}

We now define the internally efficient equilibrium.

Definition 3 Given policy $(G, b, T, \tau, L, D)$, a tax-distorted internally efficient competitive search equilibrium in the steady state consists of an unemployment value $U$, employment and firm value

\footnotetext{
${ }^{23}$ Notice that the value of a filled job with known match productivity does not change over time as it does not depend on policy parameters.
} 
functions $E, J:[z, y] \rightarrow \mathbb{R}$, a search intensity function $\hat{s}:[z, y] \rightarrow \mathbb{R}_{+}$, a queue length function $Q:[z, y] \rightarrow \mathbb{R}_{+} \cup\{\infty\}$, a single-wage contract $w$, and a match-termination policy such that

i) The value functions $E$ and $J$ solve the functional equations (24)-(25).

ii) Internal efficiency:

For any $\pi \in \Pi, w^{\prime} \in[z, y]$, a match is dissolved if its specific productivity $\pi$ is below the reservation value $R_{w^{\prime}}$, which is determined by the equilibrium condition (22).

iii) Firm's profit maximization and zero-profit condition:

For any $w^{\prime} \in[z, y], \eta\left(Q\left(w^{\prime}\right)\right) J\left(w^{\prime}\right) \leq k$, and this holds with equality at $w$.

iv) Worker's optimal search:

For any $w^{\prime} \in[z, y], Q\left(w^{\prime}\right)$ and $\hat{s}\left(w^{\prime}\right)$ satisfy condition (23). In particular,

$$
r U=v(z+b-T)-\phi(\hat{s}(w))+\hat{s}(w) \nu(Q(w))(E(w)-U)
$$

v) The government's budget is balanced intertemporarily:

$$
T+\tau w(1-u)+\operatorname{Le} \alpha F(R)=b u+G+r D
$$

The equilibrium definition is the continuous time counterpart of Definition 2; hence, we omit redundant explanations. Equation (28) is the government's budget constraint in the steady state. The left hand side is total government's revenue raised from lump sum, income and layoff taxes, whereas total costs are displayed on the right hand side, i.e. UI benefits, government spending and interest on debt.

We turn now to characterize the equilibrium tuple $(q, R, w, s)$ that takes part of the internally efficient equilibrium allocation in the steady state given policy $(G, b, T, \tau, L, D)$. We will restrict attention to the case with a positive productivity threshold hereafter. The following proposition states the necessary conditions that the equilibrium tuple must satisfy in addition to the internal efficiency condition (31) and the zero-profit condition (32). The equilibrium condition (29) equates 
the marginal costs and benefits of search intensity. Condition (30) is the dynamic counterpart of equation (19), and determines the equilibrium queue length equating the marginal expected profits and costs of an additional vacancy after substituting out the equilibrium wages.

Proposition 5.1 Given steady-state policy $(G, b, T, \tau, L, D)$, the steady-state equilibrium tuple $(q, R, w, s)$ is a solution of the maximization problem

$$
\begin{array}{ll}
\max _{q, R, w, s} & \{-\phi(s)+s \nu(q)(E(w)-U)\} \\
\text { s. to } & \eta(q) J(w)=k \text { and condition (22) }
\end{array}
$$

Consider $R>0$. The steady-state tuple must satisfy the following necessary conditions

$$
\begin{aligned}
\phi^{\prime}(s) & =\nu(q)(E(w)-U) \\
\eta(q)(1-\varphi(q))\left(\frac{\bar{\pi}-R+\alpha(1-F(R)) \frac{\mathbb{E}(\pi \mid R)-R}{r+\lambda}}{r+\lambda-\alpha)}=\right. & k \\
\frac{v\left(\chi_{e}\right)-r U}{(r+\lambda) v^{\prime}\left(\chi_{e}\right)(1-\tau)}+\frac{R y-w}{r+\lambda} & =-L \\
\eta(q) J(w) & =k
\end{aligned}
$$

The following proposition states the necessary conditions to attain constrained efficiency in the market economy.

Proposition 5.2 Consider $R>0$. To attain constrained efficiency in the steady state in the market economy, the public policy must ensure that the following two conditions must be satisfied: $L=0$, and

$$
-\tau\left(\frac{k s}{q} \frac{\varphi(q)}{1-\varphi(q)}+R y\right)=b
$$

The characterization of the planner's steady-state allocation is postponed to Appendix 8.4.1. The set of conditions that the optimal policy must satisfy are in line with the results derived in the two-period economy. First, regarding the job-creation margin, the only difference between the equilibrium equation (30) and its planner's counterpart (equation (69) in the Appendix) is the layoff tax. Therefore, layoff taxes must be zero so as not to distort job creation. Second, income 
tax rates must be negative if unemployment benefits are positive in order to efficiently set the match-termination margin. To see this, it is worth writing here the internal efficiency condition from the planner's problem (equation (68) in the Appendix):

$$
\frac{v\left(c_{e}\right)-r U}{(r+\lambda) v^{\prime}\left(c_{e}\right)}+\frac{c_{u}-c_{e}-s \nu(q) \frac{E-U}{v^{\prime}\left(c_{e}\right)}}{r+\lambda}+\frac{R y-z-s \nu(q) \frac{k}{\eta(q)} \frac{1}{1-\varphi(q)}}{r+\lambda}+\frac{1}{r+\lambda} \frac{k s}{q}=0
$$

where $E$ and $U$ denote the employment and unemployment values promised by the planner. This is the dynamic counterpart of the two-period-economy condition (6). The first term of the left hand side is the difference between employment and unemployment values (instead of the consumption utility difference) because in the dynamic setting the worker can search for a job after a match dissolution. The second term captures the consumption variation over time if separated due to potential employment in the future. The third term amounts to the excess of output that the worker produces if she stays with the firm with match-specific productivity $R$ relative to becoming unemployed and potentially producing in the future when becoming employed. The last term amounts to the savings in vacancy creation costs that are obtained if the match is not terminated.

Condition (33) together with a zero layoff tax ensures that the market and planner's internal efficiency conditions (31) and (34) coincide with one another. Condition (33) is the dynamic counterpart of equation (21), and only differs in the first term, which captures the benefits and costs associated to the search option in the dynamic setting.

\section{Steady-State Quantitative Analysis}

In this section, we first calibrate the model described in the previous section to match some salient features of the U.S. labor market. Then, we quantitatively explore differences between the calibrated steady-state equilibrium and other steady-state equilibrium allocations that differ from the benchmark in the set of policy instruments a government implements. The most significant result is that the actual unemployment insurance is excessively generous, in line with Krusell et al. (2010), which affects agents' decisions in the labor market and, particularly, hires and separations. Furthermore, the theoretical results of the previous sections also hold when comparing steady-state allocations. 


\begin{tabular}{c|c|c|c}
\hline \hline Parameter & Description & Value & Target \\
\hline \hline$\phi_{0}$ & Scale factor of search cost & 1.350 & Monthly UE rate \\
$\phi_{1}$ & Curvature of search cost & 1.096 & Elasticity of avg. unemp. duration wrt. benefits \\
$\psi$ & Meeting technology parameter & 0.730 & Elasticity of job-filling rate wrt. tightness \\
\hline$k$ & Vacancy cost & 3.344 & 20\% avg. quarterly wage per hire \\
\hline$b$ & Unemployment benefits & 0.185 & $25 \%$ of avg. wage \\
\hline$z$ & Home production & 0.310 & $\chi_{u}=0.85 \chi_{e}$ \\
\hline$\lambda$ & Exog. job-separation rate & 0.005 & Monthly EU rate \\
$\alpha$ & Learning speed parameter & 0.190 & Quarterly EU rates at the 3rd and 6th quarters \\
$\delta$ & Productivity dist. parameter & 3.330 & of job tenure (relative to the 2nd quarter) \\
\hline \hline
\end{tabular}

Table 1: Calibration

Calibration. We briefly summarize the calibration strategy, postponing further details to Section 8.5 in the Appendix. Our exercise is in line with the strategy followed by Menzio and Shi (2011), from which we take the actual elasticity of the job-finding rate with respect to market tightness as well as the actual monthly EU and UE transition rates. ${ }^{24}$ The parameter values can be found in Table 1. We calibrate the model at monthly frequency. Regarding the functional forms, we assume an exponential distribution of match-specific productivities with parameter $\delta$, a CRRA utility function with relative risk aversion $\sigma=2$, a power function for the cost of search $\phi(s)=\phi_{0} s^{\phi_{1}}$, and a Cobb-Douglas meeting function, $\eta(q)=q^{\psi}$. We target the elasticity of the job-filling rate with respect to market tightness; hence, $\psi=0.73$. The scale factor and the curvature of the search cost function jointly determine search effort, and consequently employment chances, and its sensitivity to the relative value of unemployment. Thus, we target a 0.42 monthly UE rate and the micro-elasticity of expected unemployment duration with respect to unemployment benefits, which is estimated at 0.9 by Meyer (1990). ${ }^{25}$

More importantly for us are two sets of parameters: first, those related to the relative consumption of the unemployed (i.e. unemployment benefits $b$ and home productivity $z$ ), and, second, those related to the learning and separation processes (the exogenous separation rate $\lambda$, the speed

\footnotetext{
${ }^{24}$ As such transition rates are not time independent in the discrete-time model of Menzio and Shi (2011) -nor in ours-, they are not corrected for time aggregation bias. We handle time aggregation issues by directly correcting our continuous-time model data. For example, we compute the model monthly EU transition rates for workers in a match of known productivity as

$$
\int_{0}^{1} e^{-\lambda t} \lambda e^{-s \nu(q)(1-t)} d t
$$

where the last factor within the integral ensures that no transition back to employment takes place. We do not account for further transitions in and out of employment as deemed second order.

${ }^{25}$ As Mitman and Rabinovich (2015), we take this estimate as the effect of benefits on search effort without changes in aggregate equilibrium variables.
} 
of learning $\alpha$ and the parameter of the distribution of match-specific productivities $\delta$ ). Regarding the former, following Hall and Milgrom (2008), we target an average benefit-wage ratio of 0.25 and a ratio of consumption of the unemployed to the consumption of the employed equal to 0.85 . Regarding the latter, we target the monthly EU rate as well as the ratio of EU transition rates at the third and sixth quarters of a new employment relationship to the EU rate at the second quarter using the quarterly EU rates reported in Choi and Fernández-Blanco (2016). This strategy is in line with Moscarini (2003), who also uses the job tenure profile of the separation rates to calibrate the match quality-learning rate, and with Menzio and Shi (2011), who use it to calibrate the parameters of the match quality distribution.

In accordance with the dynamic setting outlined in Section 5, the government faces an intertemporal budget constraint, whose general expression is ${ }^{26}$

$$
b u+G+r D=\tau(w(1-u)+b u)+T
$$

In the calibrated economy, the government raises revenue through a proportional income tax $\tau$ to finance unemployment benefits $b$ and the sum of the government spending and the interest on debt, while the lump sum tax $T=0$. Following Krusell et al. (2011), we set the income tax rate at $\tau=0.30$. The residual of the budget constraint is the time-invariant exogenous public spending $G$ and interest on debt $r D$.

Policy Analysis. In what follows, we numerically compare the calibrated economy with three alternative ones that we refer to as laissez-faire (LF), first-optimal (OP1) and second-optimal (OP2) economies. In all counterfactual economies, the sum $G+r D$ is taken as given and equal to its calibrated value in the benchmark economy. The alternative economies differ in the fiscal instruments. Specifically, in the LF economy, there are no unemployment benefits, and a proportional income tax is levied to finance public spending and interest on debt. In contrast, unemployment benefits, an income tax and a lump sum tax are set to maximize social welfare in the OP1 economy, while we

\footnotetext{
${ }^{26}$ Notice the two differences with respect to equation (28): First, layoff taxes are no longer considered, and, second, UI benefits are also taxable income as is the case in the U.S. The reason why a layoff tax is not considered in our quantitative work is that the optimal tax turns out highly negative becoming a fiscal instrument to smooth expenses intertemporally when public debt cannot be issued. If layoff taxes are restricted to be nonnegative, then the optimal tax is zero in line with our theoretical analysis.
} 
restrict attention to welfare-maximizing policies without lump sum taxation in the OP2 economy. We use a steady-state utilitarian social welfare function, given by

$$
S W=u U+e E(w)+(1-u-e) E_{2}(w)
$$

where $U$ and $E(w)$ denote the steady-state equilibrium values defined by the Bellman equations (23) and $(24), E_{2}(w) \equiv \frac{v\left(\chi_{e}\right)+\lambda U}{r+\lambda}$, and $w$ is the equilibrium wage. Likewise, $u$ and $e$ stand for the steady-state levels of unemployed agents and workers in matches with unknown productivity defined by the laws of motion (26) and (27), respectively.

\begin{tabular}{lcccc}
\hline \hline & Baseline & LF & OP2 & OP1 \\
\hline$\quad$ Policy & & & & \\
Lump sum tax & 0.0000 & 0.0000 & 0.0000 & 0.5073 \\
Income tax & 0.3000 & 0.2748 & 0.2761 & -0.4069 \\
Net benefits: $b(1-\tau)-T$ & 0.1293 & 0.0000 & 0.0495 & 0.0066 \\
Implied tax rate: $\tau+T / w$ & 0.3000 & 0.2748 & 0.2761 & 0.2694 \\
\hline$\quad$ Equilibrium & & & & \\
Reservation productivity & 0.6666 & 0.6518 & 0.6543 & 0.6932 \\
Queue length & 15.7621 & 12.9853 & 13.5669 & 23.7920 \\
Wages (before taxes $)$ & 0.7390 & 0.7324 & 0.7336 & 0.7501 \\
Search intensity & 1.1522 & 7.2014 & 5.3076 & 6.8006 \\
\hline$\quad$ Labor market & & & & \\
Unemployment rate & 0.0640 & 0.0099 & 0.0136 & 0.0137 \\
Output per worker & 0.8388 & 0.8317 & 0.8330 & 0.8504 \\
Monthly UE rate & 0.4214 & 0.9728 & 0.9276 & 0.9444 \\
Monthly EU rate & 0.0263 & 0.0085 & 0.0114 & 0.0116 \\
Monthly turnover rate & 0.0551 & 0.0182 & 0.0242 & 0.0247 \\
\hline$\quad$ Welfare & & & & \\
Total output & 0.7851 & 0.8235 & 0.8271 & 0.8388 \\
Consumption unemployed $\left(\chi_{u}\right)$ & 0.4397 & 0.3104 & 0.3466 & 0.3170 \\
Consumption employed $\left(\chi_{e}\right)$ & 0.5173 & 0.5311 & 0.5311 & 0.5480 \\
Ratio $\chi_{u} / \chi_{e}$ & 0.8500 & 0.5844 & 0.6526 & 0.5784 \\
Social Welfare & -263.97 & -253.03 & -252.61 & -248.58 \\
\hline \hline
\end{tabular}

Table 2: Calibrated economy and counterfactual exercises. Note: LF stands for laissez-faire equilibrium; OP1 and OP2 stand for the equilibrium allocations with policy instruments $\{b, \tau, T\}$ and $\{b, \tau\}$, respectively. Turnover rate is defined as hires plus separations over total employment.

Table 2 presents the steady-state equilibrium allocation for all these different scenarios. To summarize fiscal policies across economies, we compute a measure of net benefits received by unemployed workers, $b(1-\tau)-T$, and a measure of the implied tax rate on wages, $\tau+T / w$. In terms of labor market variables, we report the unemployment rate, monthly UE and EU rates as well as monthly worker turnover, defined as the sum of hires and separations over total employment. We also report total output, output per worker, and consumption. The second column of the table 
shows the calibrated economy, the third column corresponds to the laissez-faire economy, and the fourth and fifth columns show steady-state outcomes of the $O P 2$ and $O P 1$ economies, respectively.

The lack of publicly-provided unemployment insurance in the laissez-faire economy impacts all labor market variables. Specifically, when comparing the LF and OP1 economies, the results are in line with our previous theoretical analysis despite the OP1 being the steady-state-welfaremaximizing allocation. In particular, the LF reservation productivity and, hence, endogenous separations are suboptimally low, while the reciprocal of the queue length and the search intensity and, hence, the job-finding rate are suboptimally high. As a result, the unemployment rate is excessively low in the LF economy. Furthermore, notice that the signs of the optimal policy instruments in the OP1 economy are the predicted ones from the theoretical analysis. Importantly, unemployment benefits affect the job composition in the economy: output per worker and wages increase with benefits because the public provision of insurance raises the reservation productivity. Total output is also higher in the OP1 economy as the small unemployment increase is offset by the gains in output per worker.

We now turn to the comparison between the baseline and the OP1 and OP2 economies. From both optimal policy exercises, we conclude that the generosity of the unemployment insurance in the baseline is suboptimally high as net benefits (as well as implied tax rates) are higher than their optimal counterparts. ${ }^{27}$ It is worth highlighting that our calibration strategy for unemployment benefits is fairly conservative as it is in the lower part of the range of replacement rate values used in the literature. This generosity translates into higher unemployment and turnover rates and consumption for the unemployed as well as a lower consumption for the employed and output in the calibrated economy. ${ }^{28}$ Furthermore, the government's ability to levy lump sum taxes affects not only total welfare, but also significantly worker turnover and output per worker as such taxes eliminate distortions on key margins.

To assess the robustness of our numerical experiments, in Section 8.6 of the Appendix we conduct a number of alternative exercises considering (separately) an economy with (1) neither government spending nor debt, (2) different values for home production and (3) different levels of

\footnotetext{
${ }^{27}$ Notice that welfare in the baseline is lower than in the LF economy.

${ }^{28}$ The baseline turnover rate is higher despite higher net benefits. This is due to quite similar endogenous separations and much larger hirings in the baseline because the lower job-finding rate is offset by the higher unemployment rate.
} 
risk aversion. The results are consistent across all these scenarios. In particular, net unemployment benefits and worker turnover are excessively generous and low, respectively, in all these alternative calibrated economies.

\section{Conclusions}

In this paper we study the optimal allocation of risk-averse workers in a laissez-faire economy with various forms of market incompleteness and search and information frictions. We show that in equilibrium private markets suboptimally use the job-creation and match-termination margins to insure workers against unemployment risks. We also prove that unemployment insurance not only yields welfare gains, but also improves job composition as output per worker and wages increase with benefits. The implementation of the planner's allocation also requires wage subsidies and a zero layoff tax. Finally, we calibrate an infinite horizon model to the U.S. economy. The main result from our quantitative exercise is that unemployment benefits are suboptimally high, which affects the job-creation and match-termination margins.

\section{Appendix}

\subsection{Proofs of Section 3.}

Proof of Proposition 3.1.

To show that there exists a constrained efficient allocation, let us assume that the consumption functions while employed are indeed constant in $\pi$, so $c_{2}(\pi)=c_{2}$. This is a necessary condition for an interior solution of the planner's problem (4) as shown below, and assuming it now simplifies the proof of existence. The objective function is continuous in all its arguments. The tuple $\left(q, R, c_{u}, c_{1}, c_{2}, s\right)$ such that all consumption levels equal $z, s=0$, and the reservation probability takes any value, satisfies the two constraints. Furthermore, the domain is a compact set. Therefore, the Weierstrass Theorem applies to ensure the existence of a solution of the maximization problem. Assumption (1) implies a nontrivial solution with positive vacancy creation. 
We now characterize the planner's solution. The Lagrangian is

$$
\begin{aligned}
\mathcal{L}= & -\phi(s)+s \nu(q)\left(v\left(c_{1}\right)-v\left(c_{u}\right)+\beta \int_{R}\left(v\left(c_{2}(\pi)\right)-v\left(c_{u}\right)\right) d F(\pi)\right)+v\left(c_{u}\right)(1+\beta) \\
& +\xi_{1}\left(\phi^{\prime}(s)-\nu(q)\left(v\left(c_{1}\right)-v\left(c_{u}\right)+\beta \int_{R}\left(v\left(c_{2}(\pi)\right)-v\left(c_{u}\right)\right) d F(\pi)\right)\right)-\xi_{2} k \frac{s}{q} \\
& +\xi_{2}\left(\left(z-c_{u}\right)((1-s \nu(q))(1+\beta)+s \nu(q) F(R) \beta)+s \nu(q)\left(\bar{\pi} y-c_{1}+\beta \int_{R}\left(\pi y-c_{2}(\pi)\right) d F(\pi)\right)\right)
\end{aligned}
$$

where $\xi_{1}$ and $\xi_{2}$ are the Lagrangian multipliers.

We next differentiate the Lagrangian to obtain the necessary first order conditions. First, the functional derivatives with respect to $c_{2}(\pi)$ along with the derivative with respect to $c_{2}$ imply

$$
\begin{array}{r}
c_{1}=c_{2}(\pi)=c \\
v^{\prime}(c)\left(s-\xi_{1}\right)=s \xi_{2}
\end{array}
$$

Second, the derivative of the Lagrangian with respect to $s$ delivers the following first order condition.

$$
\begin{aligned}
\xi_{1} \phi^{\prime \prime}(s) & =\xi_{2}\left(\frac{k}{q}+\nu(q)\left[(1+\beta(1-F(R)))\left(z-c_{u}+c\right)-y(\bar{\pi}+\beta(1-F(R)) \mathbb{E}(\pi \mid R))\right]\right) \\
\left(3 \& \Leftrightarrow \xi_{1} s \phi^{\prime \prime}(s)\right. & =\xi_{2}\left(z-c_{u}\right)(1+\beta),
\end{aligned}
$$

where $\mathbb{E}(\pi \mid R) \equiv \int_{R} \pi \frac{d F(\pi)}{1-F(R)}$ denotes the conditional expected value, and the last condition comes out after using the second constraint, which must hold with equality. This implies that $\xi_{1}<0$ if and only if $c_{u}>z$.

Now, differentiating with respect to $c_{u}$, using (37), and simplifying, we have

$$
\left(v^{\prime}(c)-v^{\prime}\left(c_{u}\right)\right) \nu(q)(1+\beta(1-F(R)))\left(s-\xi_{1}\right)+(1+\beta)\left(v^{\prime}\left(c_{u}\right)-\xi_{2}\right)=0
$$

The left hand side is $\frac{\partial \mathcal{L}}{\partial c_{u}}$. To show that $z<c_{u}$, it suffices to show that the derivative of the Lagrangain evaluated at $c_{u} \leq z$ is strictly positive. To see this, notice that expression (38) together with $c_{u} \leq z$ implies $\xi_{1} \geq 0$, which together with equation (37) implies $v^{\prime}(c) \geq \xi_{2}$. The inequality 
$v^{\prime}\left(c_{u}\right)>v^{\prime}(c) \geq \xi_{2}$ follows from the concavity of the utility function and the assumption that $z<c$. We can rearrange the left hand side of the above expression as

$$
(1+\beta)\left(v^{\prime}(c)-\xi_{2}\right)+\left(v^{\prime}\left(c_{u}\right)-v^{\prime}(c)\right)\left(1+\beta-s \nu(q)(1+\beta(1-F(R)))\left(1-\xi_{1} / s\right)\right)
$$

Since the derivative evaluated at $c_{u} \leq z$ is strictly positive, it must be the case that $z<c_{u}$.

Similarly, to show that $c_{u}<c$, it suffices to show that the derivate of the Lagrangian for $c_{u} \geq c$ is strictly negative. This result follows from the left hand side of equation (39) and $\xi_{2}>v^{\prime}(c)>v^{\prime}\left(c_{u}\right)$ due to expressions (37) and (38).

Next, we look at the necessary condition for the reservation productivity. After some manipulations, we obtain

$$
\frac{\partial \mathcal{L}}{\partial R}=-\nu(q) \beta\left(s-\xi_{1}\right) d F(R) v^{\prime}(c)\left(\frac{v(c)-v\left(c_{u}\right)}{v^{\prime}(c)}+c_{u}-z+R y-c\right) \leq 0,
$$

and $R \geq 0$, with complementary slackness

The derivative is nonpositive if and only if $\frac{v(c)-v\left(c_{u}\right)}{v^{\prime}(c)}+c_{u}-z+R y-c \geq 0$, which leads to expression (6).

To see that $R y<z$, consider the nontrivial case of $R>0$. Then, the necessary first order condition becomes $\frac{v(c)-v\left(c_{u}\right)}{v^{\prime}(c)}+c_{u}-z+R y-c=0$. As $\frac{v(c)-v\left(c_{u}\right)}{v^{\prime}(c)}+c_{u}-c>0$ because of the concavity of the utility function, it must be the case that $R y<z$.

The last necessary FOC condition is with respect to the ratio $q$. After some manipulations, we obtain

(41) $(1-\varphi(q))(1+\beta(1-F(R)))\left(\frac{v(c)-v\left(c_{u}\right)}{v^{\prime}(c)}+c_{u}-z+y \frac{\bar{\pi}+\beta(1-F(R)) \mathbb{E}(\pi \mid R)}{1+\beta(1-F(R))}-c\right)=\frac{k}{\eta(q)}$

Indeed, if $R>0$, then using condition (40), we can rewrite it as

$$
(1-\varphi(q))(1+\beta(1-F(R)))\left(\frac{\bar{\pi}+\beta(1-F(R)) \mathbb{E}(\pi \mid R)}{1+\beta(1-F(R))}-R\right) y=\frac{k}{\eta(q)} \cdot \|
$$




\subsection{Proofs of Section 4.}

\section{Proof of Proposition 4.1.}

Let $\left(Q, R, w_{1}, w_{2}, s, U\right)$ be an equilibrium allocation. We first show that the tuple $\left(q, R, w_{1}, w_{2}, s\right)$ solves the maximization problem (10), where $q=Q\left(w_{1}, w_{2}\right)$. The proof is by contradiction. Suppose that there exists another tuple $\left(q^{\prime}, R^{\prime}, w_{1}^{\prime}, w_{2}^{\prime}, s^{\prime}\right)$ such that the two constraints hold, and

$$
\begin{array}{r}
\nu\left(q^{\prime}\right)\left(v\left(w_{1}^{\prime}\right)-v(z)+\beta \int_{R^{\prime}}\left(v\left(w_{2}^{\prime}\right)-v(z)\right) d F(\pi)\right) \\
>\nu(q)\left(v\left(w_{1}\right)-v(z)+\beta \int_{R}\left(v\left(w_{2}\right)-v(z)\right) d F(\pi)\right) \\
\geq \nu\left(Q\left(x^{\prime}\right)\right)\left(v\left(w_{1}^{\prime}\right)-v(z)+\beta \int_{R^{\prime}}\left(v\left(w_{2}^{\prime}\right)-v(z)\right) d F(\pi)\right),
\end{array}
$$

where $Q\left(x^{\prime}\right)$ denotes the off-the-equilibrium queue length for contract $x^{\prime}=\left(w_{1}^{\prime}, w_{2}^{\prime}\right)$. The last inequality results from the definition of equilibrium. It follows from the monotonicity of function $\nu$ that $q^{\prime}<Q\left(x^{\prime}\right)$. The second equilibrium condition in Definition 1 ensures that

$$
\begin{aligned}
k= & \eta(q)\left(\bar{\pi} y-w_{1}+\beta \int_{R}\left(\pi y-w_{2}\right) d F(\pi)\right) \\
\geq & \eta\left(Q\left(x^{\prime}\right)\right)\left(\bar{\pi} y-w_{1}^{\prime}+\beta \int_{R^{\prime}}\left(\pi y-w_{2}^{\prime}\right) d F(\pi)\right) \\
> & \eta\left(q^{\prime}\right)\left(\bar{\pi} y-w_{1}^{\prime}+\beta \int_{R^{\prime}}\left(\pi y-w_{2}^{\prime}\right) d F(\pi)\right) \geq k,
\end{aligned}
$$

where the last inequality comes from the monotonicity of function $\eta$ and $q^{\prime}<Q\left(x^{\prime}\right)$. This is a contradiction. Therefore, the equilibrium tuple solves program (10).

Now, let $\left(q, R, w_{1}, w_{2}, s\right)$ be a solution of the maximization problem (10). We define the equilibrium worker's market value as

$$
U=-\phi(s)+s \nu(q)\left(v\left(w_{1}\right)-v(z)+\beta \int_{R}\left(v\left(w_{2}\right)-v(z)\right) d F(\pi)\right)+v(z)(1+\beta)
$$

Likewise, we define the value of the queue length function $Q$ at any submarket $x^{\prime}$ as the value $q^{\prime}$ 
that satisfies

$$
U=\max _{s}-\phi(s)+s \nu\left(q^{\prime}\right)\left(v\left(w_{1}^{\prime}\right)-v(z)+\beta \int_{R^{\prime}}\left(v\left(w_{2}^{\prime}\right)-v(z)\right) d F(\pi)\right)+v(z)(1+\beta),
$$

if it exists, and $q^{\prime}=0$, otherwise.

It remains to show that firms maximize profits. That is, there is no submarket $x^{\prime}$ such that

$$
\eta\left(Q\left(x^{\prime}\right)\right)\left(\bar{\pi} y-w_{1}^{\prime}+\beta \int_{R^{\prime}}\left(\pi y-w_{2}^{\prime}\right) d F(\pi)\right)>k
$$

where $R^{\prime}$ satisfies equilibrium condition (7). We will prove it by contradiction again. Suppose there is such a $x^{\prime}$. Then, by the limit conditions and the continuity of function $\eta$, there must exist $q^{\prime}<Q\left(x^{\prime}\right)$ such that

$$
\eta\left(q^{\prime}\right)\left(\bar{\pi} y-w_{1}^{\prime}+\beta \int_{R^{\prime}}\left(\pi y-w_{2}^{\prime}\right) d F(\pi)\right)=k
$$

Since $\left(q^{\prime}, R^{\prime}, w_{1}^{\prime}, w_{2}^{\prime}, s^{\prime}\right)$ satisfies the constraints of the maximization problem, it follows that

$$
\begin{array}{r}
\nu(q)\left(v\left(w_{1}\right)-v(z)+\beta \int_{R}\left(v\left(w_{2}\right)-v(z)\right) d F(\pi)\right) \\
\geq \nu\left(q^{\prime}\right)\left(v\left(w_{1}^{\prime}\right)-v(z)+\beta \int_{R^{\prime}}\left(v\left(w_{2}^{\prime}\right)-v(z)\right) d F(\pi)\right) \\
>\nu\left(Q\left(x^{\prime}\right)\right)\left(v\left(w_{1}^{\prime}\right)-v(z)+\beta \int_{R^{\prime}}\left(v\left(w_{2}^{\prime}\right)-v(z)\right) d F(\pi)\right),
\end{array}
$$

which contradicts the definition of $Q\left(x^{\prime}\right)$.

Existence of equilibrium follows from the Weierstrass Theorem because the objective function is continuous and the domain is a nonempty compact set because of assumption (1).

We now characterize the equilibrium allocation. The Lagrangian of the maximization problem is

$$
\begin{aligned}
\mathcal{L}= & -\phi(s)+s \nu(q)\left(v\left(w_{1}\right)-v(z)+\beta \int_{R}\left(v\left(w_{2}\right)-v(z)\right) d F(\pi)\right) \\
& +\xi\left(\eta(q)\left(\bar{\pi} y-w_{1}+\beta \int_{R}\left(\pi y-w_{2}\right) d F(\pi)\right)-k\right)
\end{aligned}
$$

where $\xi$ is the Lagrange multiplier, and $R$ is determined by the equilibrium condition (7) evaluated 
at wage $w_{2}$. We differentiate the Lagrangian to obtain the necessary conditions. First, from the derivatives with respect to $w_{1}$ and $w_{2}$, we obtain, regardless of whether $R$ is zero or positive,

$$
\begin{gathered}
w_{1}=w_{2}=w \\
s v^{\prime}(w)=\xi q
\end{gathered}
$$

The necessary first order conditions with respect to $s$ and $q$ are, after some manipulations,

$(44) \phi^{\prime}(s)=\nu(q)(v(w)-v(z))(1+\beta(1-F(R)))$

$$
k=\eta(q)(1-\varphi(q))(1+\beta(1-F(R)))\left(\frac{v(w)-v(z)}{v^{\prime}(w)}+y \frac{\bar{\pi}+\beta(1-F(R)) \mathbb{E}(\pi \mid R)}{1+\beta(1-F(R))}-w\right)
$$

which are conditions (12) and (13), respectively. Therefore, these two necessary first order conditions plus the two constraints characterize the equilibrium tuple $(q, w, R, s)$.

Finally, if $R>0$, it is convenient to combine the last first order condition, equilibrium condition (7) and the zero-profit condition to obtain

$$
\begin{aligned}
w & =\varphi(q) \frac{\bar{\pi}+\beta(1-F(R)) \mathbb{E}(\pi \mid R)}{1+\beta(1-F(R))} y+(1-\varphi(q)) R y \\
k & =\eta(q)(1-\varphi(q))(\bar{\pi}+\beta(1-F(R)) \mathbb{E}(\pi \mid R)-R(1+\beta(1-F(R)))) y
\end{aligned}
$$

It is worth noticing for later use that the expression within parentheses in the last equation, $\bar{\pi}+$ $\beta(1-F(R)) \mathbb{E}(\pi \mid R)-R(1+\beta(1-F(R)))$, is a decreasing function of $R$. $\|$

\section{Proof of Lemma 4.2}

1. Consider two economies such that the utility function in the second economy, $v_{B}$, is a concave monotonic transformation of its counterpart in the first economy, $v_{A}$. That is, $v_{B}=g \circ v_{A}$, for some increasing and concave function $g$. Let $\left(q_{A}, R_{A}, w_{A}, s_{A}\right)$ and $\left(q_{B}, R_{B}, w_{B}, s_{B}\right)$ be the respective equilibrium vectors. Now, consider the maximization problem (10) and the problem that results from removing the internal efficiency condition, which we will refer to as the unconstrained problem. We will proceed with the latter because of the redundancy of the internal efficiency condition as the solution to the unconstrained problem satisfies it. 
Now, the vector $\left(q_{B}, R_{B}, w_{B}, s_{B}\right)$ belongs to the domain of the program corresponding to the economy with utility function $v_{A}$, and vice versa, because the nonnegative-profits constraint does not depend on how risk averse workers are. Therefore,

$$
\begin{aligned}
& \nu\left(\left(q_{B} 8\right)\right)\left(v_{B}\left(w_{B}\right)-v_{B}(z)\right)\left(1+\beta\left(1-F\left(R_{B}\right)\right)\right) \geq \nu\left(q_{A}\right)\left(v_{B}\left(w_{A}\right)-v_{B}(z)\right)\left(1+\beta\left(1-F\left(R_{A}\right)\right)\right) \\
& \nu\left(q_{A}\right)\left(v_{A}\left(w_{A}\right)-v_{A}(z)\right)\left(1+\beta\left(1-F\left(R_{A}\right)\right)\right) \geq \nu\left(q_{B}\right)\left(v_{A}\left(w_{B}\right)-v_{A}(z)\right)\left(1+\beta\left(1-F\left(R_{B}\right)\right)\right)
\end{aligned}
$$

The proof of $w_{B}<w_{A}$ is identical to the proof of Proposition 2 in Acemoglu and Shimer (1999); hence, we omit it.

Now, we will show that $q_{B}<q_{A}$ and $R_{B}<R_{A}$ or $R_{B}=R_{A}=0$. Let us distinguish between two cases.

Case 1: $R_{A}, R_{B}>0$ or $R_{A}=R_{B}=0$. We prove by contradiction that $q_{B}<q_{A}$. That is, suppose that the opposite is true: $q_{B} \geq q_{A}$. Then, the equilibrium condition (47) implies that $R_{B} \geq R_{A}$. Since $q_{B} \geq q_{A}, R_{B} \geq R_{A}$ and $w_{B}<w_{A}$, expression (48) cannot hold, which is a contradiction. Therefore, $q_{B}<q_{A}$, and $R_{B}<R_{A}$ follows again from condition (47) if $R_{A}, R_{B}>0$.

Case 2: $R_{A}=0<R_{B}$. We will show that this case cannot occur in equilibrium. Following the same argument as before, we obtain that $q_{B}<q_{A}$. The necessary equilibrium condition (45) together with the monotonicity of functions $\eta$ and $\varphi$ implies

$$
\begin{array}{r}
\left(1+\beta\left(1-F\left(R_{A}\right)\right)\right)\left(\frac{v_{A}\left(w_{A}\right)-v_{A}(z)}{v_{A}^{\prime}\left(w_{A}\right)}-w_{A}+y \frac{\bar{\pi}+\beta\left(1-F\left(R_{A}\right)\right) \mathbb{E}\left(\pi \mid R_{A}\right)}{1+\beta\left(1-F\left(R_{A}\right)\right)}\right)< \\
\quad\left(1+\beta\left(1-F\left(R_{B}\right)\right)\right)\left(\frac{v_{B}\left(w_{B}\right)-v_{B}(z)}{v_{B}^{\prime}\left(w_{B}\right)}-w_{B}+y \frac{\bar{\pi}+\beta\left(1-F\left(R_{B}\right)\right) \mathbb{E}\left(\pi \mid R_{B}\right)}{1+\beta\left(1-F\left(R_{B}\right)\right)}\right)
\end{array}
$$

Since $R_{A}<R_{B}$, the first term of the left hand is bigger than its counterpart of the right hand side, and

$$
\frac{\bar{\pi}+\beta\left(1-F\left(R_{A}\right)\right) \mathbb{E}\left(\pi \mid R_{A}\right)}{1+\beta\left(1-F\left(R_{A}\right)\right)}>\frac{\bar{\pi}+\beta\left(1-F\left(R_{B}\right)\right) \mathbb{E}\left(\pi \mid R_{B}\right)}{1+\beta\left(1-F\left(R_{B}\right)\right)}
$$


Moreover, by comparing the first terms within the brackets, as $w_{A}<w_{B}$, we have

$$
\frac{v_{A}\left(w_{A}\right)-v_{A}(z)}{v_{A}^{\prime}\left(w_{A}\right)}-w_{A}>\frac{v_{B}\left(w_{B}\right)-v_{B}(z)}{v_{B}^{\prime}\left(w_{B}\right)}-w_{B}
$$

We have reached a contradiction, and, hence, the above inequality fails to hold.

2. Let $z_{B}<z_{A}$, and $\left(q_{A}, R_{A}, w_{A}, s_{A}\right)$ and $\left(q_{B}, R_{B}, w_{B}, s_{B}\right)$ be the respective equilibrium tuples. Consider the unconstrained problem associated to program (10) as defined above. As the constraint does not depend on the value of $z$, the equilibrium tuple $\left(q_{A}, w_{A}, R_{A}, s_{A}\right)$ satisfies the constraint of the program when $z=z_{B}$, and so does the vector $\left(q_{B}, w_{B}, R_{B}, s_{B}\right)$ when $z=z_{A}$. This implies

$$
\nu\left(q_{B}\right)\left(v\left(w_{B}\right)-\imath\right.
$$

$\nu\left(q_{A}\right)\left(v\left(w_{A}\right)-v\left(z_{A}\right)\right)\left(1+\beta\left(1-F\left(R_{A}\right)\right)\right) \geq \nu\left(q_{B}\right)\left(v\left(w_{B}\right)-v\left(z_{A}\right)\right)\left(1+\beta\left(1-F\left(R_{B}\right)\right)\right)$

Multiplying these two inequalities and manipulating the outcome, we obtain

$$
\begin{array}{r}
\left(v\left(w_{B}\right)-v\left(z_{B}\right)\right)\left(v\left(w_{A}\right)-v\left(z_{A}\right)\right) \geq\left(v\left(w_{A}\right)-v\left(z_{B}\right)\right)\left(v\left(w_{B}\right)-v\left(z_{A}\right)\right) \\
\Leftrightarrow\left(v\left(z_{A}\right)-v\left(z_{B}\right)\right)\left(v\left(w_{A}\right)-v\left(w_{B}\right)\right) \geq 0
\end{array}
$$

As the utility function is increasing and $z_{B}<z_{A}$, it follows that $w_{B} \leq w_{A}$. Now, we show that $q_{B} \leq q_{A}$ by contradiction. Suppose that $q_{B}>q_{A}$. Then, the monotonicity of function $\nu$ and inequality (49) imply that $R_{A}>R_{B}$. We distinguish two cases.

Case 1: $R_{B}>0$. The equilibrium condition (47) and $q_{B}>q_{A}$ imply that $R_{A}<R_{B}$ because its left hand side is a decreasing function in $R$. This is a contradiction. Therefore, $q_{B} \leq q_{A}$, and $R_{B} \leq R_{A}$ results again from condition (47).

Case 2: $R_{B}=0$. The steps are analogous to the previous case studied above. Because of 
equation (45), we obtain

$$
\begin{array}{r}
\eta\left(q_{B}\right)\left(1-\varphi\left(q_{B}\right)\right)(1+\beta)\left(\frac{v\left(w_{B}\right)-v\left(z_{B}\right)}{v^{\prime}\left(w_{B}\right)}+y \frac{\bar{\pi}+\beta \bar{\pi}}{1+\beta}-w_{B}\right)= \\
\eta\left(q_{A}\right)\left(1-\varphi\left(q_{A}\right)\right)\left(1+\beta\left(1-F\left(R_{A}\right)\right)\right)\left(\frac{v\left(w_{A}\right)-v\left(z_{A}\right)}{v^{\prime}\left(w_{A}\right)}+y \frac{\bar{\pi}+\beta\left(1-F\left(R_{A}\right)\right) \mathbb{E}\left(\pi \mid R_{A}\right)}{1+\beta\left(1-F\left(R_{A}\right)\right)}-w_{A}\right)
\end{array}
$$

Since $R_{B}=0<R_{A}$, we have from the equilibrium condition (7) that

$$
\frac{v\left(w_{B}\right)-v\left(z_{B}\right)}{v^{\prime}\left(w_{B}\right)}-w_{B} \geq 0>-R_{A} y=\frac{v\left(w_{A}\right)-v\left(z_{A}\right)}{v^{\prime}\left(w_{A}\right)}-w_{A}
$$

This together with $q_{B}>q_{A}$ and $R_{B}=0 \leq R_{A}$ implies that the above equality fails to hold. We reached a contradiction. Therefore, $q_{B} \leq q_{A}$. Obviously, in this case, $R_{B}=0 \leq R_{A}$.

It remains to show that the inequalities are strict, unless $R_{A}=R_{B}=0: w_{B}<w_{A}, q_{B}<q_{A}$ and $R_{B}<R_{A}$. Consider the case of $R_{A}, R_{B}>0$. Suppose that $w_{A}=w_{B}=w$. Then, the internal efficiency condition implies that

$$
\frac{v\left(z_{B}\right)-v\left(z_{A}\right)}{v^{\prime}(w)}+y\left(R_{A}-R_{B}\right)=0
$$

Therefore, $R_{A}>R_{B}$, and, from the equilibrium condition (47), it follows that $q_{A}>q_{B}$. Then, we can rewrite the equilibrium condition (46) as

$$
w=\frac{\bar{\pi}+\beta(1-F(R)) \mathbb{E}(\pi \mid R)}{1+\beta(1-F(R))} y+(1-\varphi(q))\left(R-\frac{\bar{\pi}+\beta(1-F(R)) \mathbb{E}(\pi \mid R)}{1+\beta(1-F(R))}\right) y
$$

The right hand side is strictly larger in equilibrium A than in B leading to a contradiction. Therefore, $w_{A}>w_{B}$, and using the same two equations it follows that $R_{A}>R_{B}$ and $q_{A}>q_{B}$. $\|$

\section{Proof of Proposition 4.3}

Let $\left(q^{p}, R^{p}, c_{u}^{p}, c^{p}, s^{p}\right)$ denote the planner's solution to problem (4). We showed in the proof of Proposition 3.1 that $z<c_{u}^{p}$. Since unemployed workers just consume their home production in the equilibrium allocation, the planner's solution cannot be decentralized in the laissez-faire economy.

Consider now the case $R^{p}>0$. Let $(q, R, w)$ take part of an internally efficient equilibrium. 
We are to show by contradiction that the equilibrium threshold $R$ and queue length $q$ are lower than $R^{p}$ and $q^{p}$, respectively. Suppose that $R \geq R^{p}$ instead. Then, because the necessary efficiency and equilibrium conditions (5) and (13) establish a positive relationship between the cutoff and the queue length, it follows that $q \geq q^{p}$. Using the necessary efficiency and equilibrium conditions (6) and the internal efficiency condition (7), we obtain

$$
\frac{v(w)-v(z)}{v^{\prime}(w)}+z-w=z-R y \leq z-R^{p} y=\frac{v\left(c^{p}\right)-v\left(c_{u}^{p}\right)}{v^{\prime}\left(c^{p}\right)}+c_{u}^{p}-c^{p}
$$

By comparing the left and right sides of this inequality, we obtain that $w<c^{p}$ because $z<c_{u}$ and the expression $\frac{v(w)-v(z)}{v^{\prime}(w)}+z-w$ is decreasing in $z$ and increasing in $w$.

Now, consider problem (10) without the internal efficiency condition, which we know is redundant. We referred to it previously as the unconstrained problem. Notice that $\left(q^{p}, R^{p}, c^{p}\right)$ satisfies the constraint of the unconstrained problem as the intertemporal resource constraint together with $z<c_{u}$ implies

$$
\eta\left(q^{p}\right)\left(\bar{\pi} y-c^{p}+\beta \int_{R^{p}}\left(\pi y-c^{p}\right) d F(\pi)\right)>k
$$

Furthermore, the tuple $\left(q^{p}, R^{p}, c^{p}\right)$ also yields a strictly higher value because

$$
\left(1+\beta\left(1-F\left(R^{p}\right)\right)\right)\left(v\left(c^{p}\right)-v(z)\right)>(1+\beta(1-F(R)))(v(w)-v(z))
$$

That is, the tuple $(q, R, w)$ cannot take part of an equilibrium allocation. Therefore, $R<R^{p}$. This implies $q<q^{p}$ according to the first order conditions (5) and (13).

Finally, to see that the equilibrium search intensity is higher than its planner's counterpart, notice again that $\left(q^{p}, R^{p}, c^{p}\right)$ satisfies the constraint of the unconstrained version of program (10). Therefore,

$$
\nu(q)(v(w)-v(z))(1+\beta(1-F(R))) \geq \nu\left(q^{p}\right)\left(v\left(c^{p}\right)-v\left(c_{u}^{p}\right)\right)\left(1+\beta\left(1-F\left(R^{p}\right)\right)\right)
$$

The planner's and equilibrium conditions (2) and (12) imply that unemployed's search intensity is higher in the market economy.\| 


\section{Proof of Proposition 4.4}

Consider a market economy in which a government implements a lump sum tax $T$, an income $\operatorname{tax} \tau$ to the employed workers, a subsidy $b$ to the unemployed, and a layoff tax $L$ in order to decentralize the constrained efficient allocation $\left(q^{p}, R^{p}, c_{u}^{p}, c^{p}, s^{p}\right)$. This requires that the following conditions hold in equilibrium:

$$
\begin{aligned}
c_{u}^{p}= & z+b-T \\
c^{p}= & w(1-\tau)-T \\
0= & (1+\beta)(T-b)(1-s \nu(q))+\beta(T-b+L) s \nu(q) F(R) \\
& +(T+\tau w) s \nu(q)(1+\beta(1-F(R)))
\end{aligned}
$$

where the last equation is the intertemporal balanced-budget constraint of the government.

The counterpart of program (10) without the internal efficiency condition in this economy with taxes is, after imposing the equilibrium result of $w_{1}=w_{2}$,

$$
\begin{array}{cc}
\max _{w, R, q, s}-\phi(s)+s \nu(q) & \left(v(w(1-\tau)-T)-v\left(c_{u}^{p}\right)+\beta \int_{R}\left(v(w(1-\tau)-T)-v\left(c_{u}^{p}\right)\right) d F(\pi)\right) \\
\text { (54) s. to } & \eta(q)\left(\bar{\pi} y-w+\beta \int_{R}(\pi y-w) d F(\pi)-\beta F(R) L\right) \geq k
\end{array}
$$

Notice that we obtain the nonnegative profits condition of the above program by combining the resource constraint of the planner (3) and the balanced-budget constraint of the government (53). That is, the above problem and the planner's problem (4) give the same solution. Therefore, if there exists a policy $(b, \tau, T, L)$ such that satisfies conditions (51)-(53), then the tax-distorted equilibrium is constrained efficient.

Consider the case of $R^{p}>0$. By combining the necessary first order conditions with respect to $q$ and $R$, we can write the former as

$$
\eta(q)(1-\varphi(q))\left(\left(\frac{\bar{\pi}+\beta(1-F(R)) \mathbb{E}(\pi \mid R)}{1+\beta(1-F(R))}-R\right) y-L \frac{1+\beta}{1+\beta(1-F(R))}\right)=\frac{k}{1+\beta(1-F(R))}
$$

This equilibrium condition coincides with the efficiency condition (42) if and only if $L=0$. 
Given $q^{p}$ and $R^{p}$, the equilibrium wage $w$ is determined by the zero-profit condition. Then, the government balanced-budget condition holds at the efficient allocation. Therefore, there are two policy instruments to be determined and two equations to be satisfied, taking into account that $b$ is such that condition (53) holds.

The efficiency condition (40) is $\frac{v\left(c^{p}\right)-v\left(c_{u}^{p}\right)}{v^{\prime}\left(c^{p}\right)}+c_{u}^{p}-z+R^{p} y-c^{p}=0$, whereas the tax-distorted equilibrium counterpart of condition $(7)$ is

$$
\frac{v^{\prime}(c)-v^{\prime}\left(c_{u}\right)}{v^{\prime}(c)(1-\tau)}+R y-w=0
$$

Then, plugging conditions (51) and (52) into the former expression, and comparing with the latter, we obtain that

$$
b=-\tau y R^{p}
$$

Therefore, $\tau<0$ if $b>0$. We use equation (56) to determine parameter $\tau$. Then, we can pin down the remaining policy parameters from equations (51) and (52).॥

\subsection{Two-period Model with Savings}

Consider a two-period economy that differs from the one set in Section 2 in the following items. At birth, all workers are endowed with assets $a$. Workers can save part of their first period wealth to increase consumption in the second period, but cannot borrow. The interest rate $r$ is exogenously determined consistent with the intertemporal resource constraint of the planner. As with our quantitative exercise, we assume that $\beta(1+r)=1 .^{29}$ There is lack of commitment on the worker's side. The timing of the events in period one is as follows: agents search for partners, then production and consumption and saving decisions take place.

\subsubsection{Planner's Economy}

The planner chooses an allocation $\left(s, q, R, c_{u}, c_{1}, c_{2 e}, c_{2 u}\right)$, where $c_{2 e}$ and $c_{2 u}$ denote the periodtwo consumption promised to the workers who are employed in period one contingent on their

\footnotetext{
${ }^{29}$ For example, Shimer and Werning (2008) also assume an interest rate equal to the discount rate.
} 
employment status in period two. To save on notation and without loss of generality, we will assume that consumption variables are not contingent on signal $\pi$. The counterpart of the intertemporal resource constraint (3) is

$$
\begin{aligned}
& \left(z-c_{u}\right)(1-s \nu(q))(1+\beta)+s \nu(q) F(R) \beta\left(z-c_{2 u}\right) \\
+ & s \nu(q)\left(y-c_{1}+\beta \int_{R}\left(\pi y-c_{2 e}\right) d F(\pi)\right)+a \geq k \frac{s}{q}
\end{aligned}
$$

There are two differences with respect to the constraint in Section 2. First, the period-two newly unemployed workers obtain consumption $c_{2 u}$. Second, the total wealth $a$ the economy starts with appears on the output side of the resource constraint as an endowment.

The counterpart of the incentive compatibility condition (2) is

$$
\phi^{\prime}(s)=\nu(q)\left(v\left(c_{1}\right)-v\left(c_{u}\right)+\beta\left((1-F(R)) v\left(c_{2 e}\right)+F(R) v\left(c_{2 u}\right)-v\left(c_{u}\right)\right)\right)
$$

The planner's problem becomes

$\max _{s, q, R, c_{u}, c_{1}, c_{2 e}, c_{2 u}}-\phi(s)+s \nu(q)\left(v\left(c_{1}\right)-v\left(c_{u}\right)+\beta\left((1-F(R)) v\left(c_{2 e}\right)+F(R) v\left(c_{2 u}\right)-v\left(c_{u}\right)\right)\right)+v\left(c_{u}\right)(1+\beta)$

s. t. conditions (58) and (59)

Lemma 8.1 The constrained efficient allocation must satisfy $z+\frac{a}{1+\beta}<c_{u}^{p}<c^{p}=c_{1}^{p}=c_{2 e}^{p}=c_{2 u}^{p}$. The reservation probability $R^{p}=\frac{z}{y}$. Furthermore,

$$
\begin{array}{r}
(1-\varphi(q))\left(\left(\frac{v\left(c^{p}\right)-v\left(c_{u}^{p}\right)}{v^{\prime}\left(c^{p}\right)}+c_{u}-c\right)(1+\beta)\right. \\
\left.+y\left(1+\beta\left(1-F\left(R^{p}\right)\right) \mathbb{E}\left(\pi \mid R^{p}\right)-R^{p}\left(1+\beta\left(1-F\left(R^{p}\right)\right)\right)\right)\right)=\frac{k}{\eta(q)}
\end{array}
$$

The results stated in the lemma follow from the first order conditions of the planner's problem. Unlike the economy analyzed in Section 2, the reservation productivity is such that a match continues if and only if market productivity lies above home productivity. 


\subsubsection{Market Economy}

Consider the following policy instruments: unemployment benefits $b$, a lump sum tax $T$, a proportional income tax rate $\tau$, and layoff taxes, $L$. For expositional convenience, we first solve the problem of workers who are always unemployed. She chooses savings to smooth consumption across periods. That is,

$$
V^{u} \equiv \max _{a^{\prime}} v\left(a+z+b-T-a^{\prime}\right)+\beta v\left(a^{\prime}(1+r)+z+b-T\right)
$$

Because the objective function is strictly concave, this problem has a unique solution, and consumption is time-invariant and equals $c_{u}=z+b-T+\frac{a}{1+\beta}$.

Next, we look at the problem of the worker who is employed in period one with wages $w_{1}$ and $w_{2}$. She chooses savings taking into account the uncertainty about period-two income (i.e. forming rational expectations about the threshold $R$ ). That is,

$$
V^{e}\left(w_{1}, w_{2}\right) \equiv \max _{a^{\prime}} v\left(c_{1}\right)+\beta\left((1-F(R)) v\left(c_{2 e}\right)+F(R) v\left(c_{2 u}\right)\right)
$$

where $c_{1}=a+w_{1}(1-\tau)-T-a^{\prime}, c_{2 e}=a^{\prime}(1+r)+w_{2}(1-\tau)-T$ and $c_{2 u}=a^{\prime}(1+r)+z+b-T$. The concavity of the objective function ensures a unique solution, which satisfies the first order condition:

$$
v^{\prime}\left(c_{1}\right)=(1-F(R)) v^{\prime}\left(c_{2 e}\right)+F(R) v^{\prime}\left(c_{2 u}\right)
$$

The lack of commitment on the worker's side implies that $w_{2}(1-\tau) \geq z+b$ since the worker would quit otherwise, and, hence, $c_{2 e} \geq c_{2 u}$. Using this inequality and equation (61), we obtain that $c_{2 e} \geq c_{1}$.

Finally, the firm's problem is to maximize expected profits subject to guaranteeing workers their 
market value $U$ and the internal efficiency condition. That is

$$
\begin{array}{cc}
\max _{q, w_{1}, w_{2}} & \eta(q)\left(y-w_{1}+\beta\left(\int_{R}\left(\pi y-w_{2}\right) d F(\pi)-F(R) L\right)\right) \\
\text { s. to } & \max _{s}\left\{-\phi(s)+s \nu(q)\left(V^{e}\left(w_{1}, w_{2}\right)-V^{u}\right)\right\}+V^{u} \geq U \\
& \frac{v\left(c_{2 e}\right)-v\left(c_{2 u}\right)}{v^{\prime}\left(c_{2 e}\right)(1-\tau)}+R y-w_{2} \geq-L, \text { and } R \geq 0, \text { with complementary slackness }
\end{array}
$$

The government is assumed to balance its budget intertemporally, as the planner in the centralized economy. Therefore, its balanced budget constraint is

$$
(T-b)((1-s \nu(q))(1+\beta)+s \nu(q) F(R) \beta)+s \nu(q)\left(T+\tau w_{1}+\beta(1-F(R))\left(T+\tau w_{2}\right)+\beta L F(R)\right)=0
$$

Given policy $(G, b, T, \tau, L)$, a tax-distorted internally efficient competitive search equilibrium consists of consumption streams and wages, a queue length function, a market value, and a reservation productivity such that agents behave optimally, and the government budget is balanced. Let us now write the Lagrangian of the firm's problem.

$$
\begin{aligned}
\mathcal{L}= & \eta(q)\left(y-w_{1}+\beta\left(\int_{R}\left(\pi y-w_{2}\right) d F(\pi)-F(R) L\right)\right) \\
& +\xi\left(\max _{s}\left\{-\phi(s)+s \nu(q)\left(V^{e}\left(w_{1}, w_{2}\right)-V^{u}\right)\right\}+V^{u}-U\right)
\end{aligned}
$$

where $R$ is determined by the internal efficiency condition. Using the Envelope Theorem, the first order conditions with respect to wages, with complementary slackness, are:

$$
\begin{aligned}
\frac{\partial \mathcal{L}}{\partial w_{1}}= & -\nu(q) d F(\pi)\left(q-\xi s(1-\tau) v^{\prime}\left(c_{1}\right)\right) \leq 0, w_{1} \geq 0 \\
\frac{\partial \mathcal{L}}{\partial w_{2}}= & -\nu(q) d F(\pi) \beta \pi\left(q-\xi s(1-\tau) v^{\prime}\left(c_{2 e}\right)\right) \leq 0, \text { and } w_{2}(1-\tau) \geq z+b \\
& \text { with complementary slackness }
\end{aligned}
$$

Workers who are employed in period one perfectly smooth consumption in equilibrium. Suppose that this is not the case and $w_{2}(1-\tau)>z+b$. Then, as reasoned above, the optimality condition (61) together with the concavity of the utility function implies that $c_{2 e}>c_{1}$. Then, it follows 
that $0 \geq \frac{\partial \mathcal{L}}{\partial w_{1}}>\frac{\partial \mathcal{L}}{\partial w_{2}}$. Therefore, a wage schedule such that $w_{2}(1-\tau)>z+b$ cannot be offered in equilibrium as firms would make higher profits by reducing the period-two wage. As a result, $w_{2}(1-\tau)=z+b$. Then, it follows from equation (61) that $c_{1}=c_{2 e}=c_{2 u}=c$. This result is quite intuitive. Firms frontload wages because of the employment uncertainty in period two and the worker's ability to transfer income across periods.

Plugging these results in the internal efficiency condition, we obtain that $R y-w_{2}=-L$. Moreover,

$$
\begin{gathered}
\frac{\partial \mathcal{L}}{\partial q}=0 \Leftrightarrow \\
\left.(1-\varphi(q))\left(\frac{v(c)-v\left(c_{u}\right)}{v^{\prime}(c)(1-\tau)}(1+\beta)+y(1+\beta(1-F(R)) \mathbb{E}(\pi \mid R))-w_{1}-w_{2} \beta(1-F(R))-F(R) \beta L\right)\right)=\frac{k}{\eta(q)}
\end{gathered}
$$

Next, using the budget constraint of the period-one employed and unemployed workers, we can isolate wages as

$$
w_{1}(1-\tau)=c(1+\beta)-\left(c_{u}-z-b+T\right)(1+\beta)-\beta(z+b)+T(1+\beta)=\left(c-c_{u}\right)(1+\beta)+z+b
$$

We can now substitute out wage $w_{1}$ in equation (63), and obtain

$$
(1-\varphi(q))(1+\beta)\left(\frac{v(c)-v\left(c_{u}\right)}{v^{\prime}(c)}+c_{u}-c-(z+b)+\frac{1-\tau}{1+\beta} y(1+\beta(1-F(R)) \mathbb{E}(\pi \mid R)+\beta F(R) R)\right)=\frac{k(1-\tau)}{\eta(q)}
$$

Consider first a laissez-faire economy, i.e. $b=T=\tau=L=0$. Then, it follows that $R y=w_{2}=z$. The reason why the reservation productivity is above the level of the no-saving case is because there is no utility gap between employment and unemployment in the second period, and, hence, maximizing the joint value of the pair amounts to maximizing firm's profits. ${ }^{30}$ Moreover, notice that the equilibrium job-creation condition coincides with the constrained efficiency condition (60) if consumption levels are the same. However, the equilibrium allocation is not constrained efficient. To see this, it suffices to notice that $c_{u}=z+\frac{a}{1+\beta}<c_{u}^{p}$ as stated in Lemma 8.1.

\footnotetext{
${ }^{30}$ The same result obtains if firms were allowed to commit to a severance payment.
} 
Next, consider a policy $(G, b, T, \tau, L)$ such that $c_{u}^{p}=z+b-T+\frac{a}{1+\beta}, c^{p}=w_{1}(1-\tau)-T$, $w_{2}(1-\tau)=z+b$, and the government budget constraint holds. Then, the internally efficient equilibrium and constrained efficiency conditions with respect to $R$ coincide with one another if and only if $z=w_{2}-L$. We now compare the constrained efficiency first order condition with respect to $q$ (60) with its equilibrium counterpart (63). After some manipulations, we obtain that they are the same if and only if

$$
-b(1+\beta)=\tau\left(\beta F\left(R^{p}\right) R^{p} y+y\left(1+\beta\left(1-F\left(R^{p}\right)\right) \mathbb{E}\left(\pi \mid R^{p}\right)\right)+\frac{k}{\eta\left(q^{p}\right)\left(1-\varphi\left(q^{p}\right)\right)}\right)
$$

The following proposition establishes that the results stated in Proposition 4.3 also hold when workers are allowed to save. As the laissez-faire equilibrium shows, future unemployment risks are efficiently covered because firms frontload wages for their employees to perfectly smooth consumption across periods and across states. This explains why layoff taxes are redundant when workers are allowed to save. Finally, it follows from the last expression that firms must be subsidized through a negative income tax.

Proposition 8.2 The laissez-faire competitive search internally efficient equilibrium is not constrained efficient. Moreover, constrained efficiency can be attained in the market economy by the implementation of an unemployment insurance system and a scheme of subsidies to match creation funded through lump sum taxes.

\subsection{Proofs of Section 5.}

\section{Proof of Proposition 5.1}

We omit the proof of the equivalence of the solution of the maximization problem and the equilibrium tuple as it does not differ from the lines in the proof of Proposition 4.1. Given the steady-state policy $(G, b, T, \tau, L, D)$, we will consider the maximization problem without the internal efficiency condition (22), as it is redundant.

The Lagrangian of the maximization problem is

$$
\mathcal{L}=-\phi(s)+s \nu(q)(E(w)-U)+\xi(\eta(q) J(w)-k),
$$


where $\xi$ is the lagrangian multiplier associated to the constraint. The necessary conditions that a solution $(q, R, w, s)$ must satisfy are:

$$
\begin{aligned}
& \frac{\partial \mathcal{L}}{\partial q}=0 \quad \Longleftrightarrow \quad(1-\varphi(q))(E(w)-U)=\xi q \varphi(q) J(w) \\
& \frac{\partial \mathcal{L}}{\partial R}=0 \quad \Longleftrightarrow \frac{v\left(\chi_{e}\right)-r U}{r+\lambda}+\xi q\left(\frac{R y-w}{r+\lambda}+L\right)=0, \text { if } R>0 \\
& \frac{\partial \mathcal{L}}{\partial w}=0 \quad \Longleftrightarrow \xi q=v^{\prime}\left(\chi_{e}\right)(1-\tau) \\
& \frac{\partial \mathcal{L}}{\partial s}=0 \quad \Longleftrightarrow \phi^{\prime}(s)=\nu(q)(E(w)-U)
\end{aligned}
$$

where $\chi_{e}=w(1-\tau)-T$. The last equation is the equilibrium condition (29), whereas equation (65) is indeed the internal efficiency condition (22) after replacing the multiplier using equation (66). We obtain equilibrium condition (30) from properly manipulating equation (64).॥

\subsubsection{Planner's Problem}

The planner sets an allocation $\left\{\left(s_{t}, q_{t}, R_{t}, c_{u t}, c_{e t}\right)\right\}_{t}$, which consists of a stream of search intensities, queue lengths, reservation productivities and consumptions to maximize the aggregate expected discounted utility of the representative worker. The dynamic counterpart of the planner's problem (4) is

$$
\begin{array}{ll}
\max & \int_{0}^{\infty} e^{-r t}\left(u_{t}\left(v\left(c_{u t}\right)-\phi\left(s_{t}\right)\right)+\left(1-u_{t}\right) v\left(c_{e t}\right)\right) d t \\
\text { s. to } & \dot{u}_{t}=\alpha F\left(R_{t}\right) e_{t}-s_{t} \nu\left(q_{t}\right) u_{t}+\lambda\left(1-u_{t}\right) \\
& \dot{e}_{t}=s_{t} \nu\left(q_{t}\right) u_{t}-(\lambda+\alpha) e_{t} \\
(\mathrm{IRC}) \quad & \int_{0}^{\infty} e^{-r t}\left(u_{t} z+e_{t} \bar{\pi}+e_{t} \alpha\left(1-F\left(R_{t}\right)\right) \frac{\mathbb{E}\left(\pi \mid R_{t}\right) y}{r+\lambda}-k \frac{s_{t} u_{t}}{q_{t}}-u_{t} c_{u t}-\left(1-u_{t}\right) c_{e t}-G_{t}\right) d t=0 \\
(\mathrm{ICC}) \quad & \phi^{\prime}\left(s_{t}\right)=\nu\left(q_{t}\right)\left(E_{t}-U_{t}\right) \\
& r U_{t}=v\left(c_{u t}\right)-\phi\left(s_{t}\right)+s_{t} \nu\left(q_{t}\right)\left(E_{t}-U_{t}\right)+\dot{U}_{t} \\
& r E_{t}=v\left(c_{e t}\right)+\left(\lambda+\alpha F\left(R_{t}\right)\right)\left(U_{t}-E_{t}\right)+\alpha\left(1-F\left(R_{t}\right)\right)\left(E_{2 t}-E_{t}\right)+\dot{E}_{t} \\
& r E_{2 t}=v\left(c_{e t}\right)+\lambda\left(U_{t}-E_{2 t}\right)+\dot{E}_{2 t} \\
& u_{0}=1, e_{0}=0
\end{array}
$$


The first two restrictions are the laws of motion of the rates of unemployment and employment with unknown match quality, respectively. The third and fourth constraints are the counterparts of the intertemporal resource constraint (3) and the incentive compatibility constraint (2). The last three restrictions are the dynamic equations that the value promised to workers in each employment state must satisfy, and the dot symbol refers to the time derivative of the respective object.

The following proposition states necessary conditions in the state state. Equation (68) is the internal efficiency condition in the dynamic setting. That is, a match is dissolved if the social joint value is negative. Equation (69) is the dynamic counterpart of the constrained efficiency condition (20) with no significant differences. Finally, the last constrained efficiency condition equates the marginal social benefits and costs of an extra unit of search intensity.

Proposition 8.3 Consider the case in which the steady-state reservation productivity is positive. The planner's steady-state allocation $\left(s^{p}, q^{p}, R^{p}, c_{u}^{p}, c_{e}^{p}\right)$ must satisfy the (ICC), and the following necessary conditions

$$
\begin{aligned}
\frac{E_{2}-U}{v^{\prime}\left(c_{e}\right)}+\frac{c_{u}-c_{e}-s \nu(q) \frac{E-U}{v^{\prime}\left(c_{e}\right)}}{r+\lambda}+\frac{R y-z-s \nu(q) \frac{k}{\eta(q)} \frac{1}{1-\varphi(q)}}{r+\lambda}+\frac{1}{r+\lambda} \frac{k s}{q} & =0 \\
\eta(q)(1-\varphi(q)) \frac{\bar{\pi}-R+\alpha(1-F(R)) \frac{\mathbb{E}(\pi \mid R)-R}{r+\lambda}}{r+\lambda+\alpha} y & =k \\
\frac{1-\varphi(q)}{\varphi(q)}\left(\frac{v^{\prime}\left(c_{u}\right)-v^{\prime}\left(c_{e}\right)}{v^{\prime}\left(c_{u}\right) v^{\prime}\left(c_{e}\right)} s \phi^{\prime \prime}(s)+\nu(q) \frac{E-U}{v^{\prime}\left(c_{e}\right)}\right) & =\frac{k}{q}
\end{aligned}
$$

\section{Proof of Proposition 8.3.}

The (IRC) can be rewritten as

$$
\dot{A}_{t}=e^{-r t}\left(u_{t} z+e_{t} \bar{\pi}+e_{t} \alpha\left(1-F\left(R_{t}\right)\right) \frac{\mathbb{E}\left(\pi \mid R_{t}\right) y}{r+\lambda} d F(\pi)-k \frac{s_{t} u_{t}}{q_{t}}-u_{t} c_{u t}-\left(1-u_{t}\right) c_{e t}-G_{t}\right)
$$

and $\quad A_{0}=A_{\infty}=0$

Let us suppress the time subindices to simplify notation. The associated current-valued Hamil- 
tonian is

$$
\begin{aligned}
H= & u\left(v\left(c_{u}\right)-\phi(s)\right)+(1-u) v\left(c_{e}\right)+\mu_{1}(\alpha F(R) e-s \nu(q) u+\lambda(1-u))+ \\
& \mu_{2}(s \nu(q) u-(\lambda+\alpha) e)+\mu_{3}\left(u z+e \bar{\pi}+e \alpha(1-F(R)) \frac{\mathbb{E}(\pi \mid R) y}{r+\lambda}-k \frac{s u}{q}-u c_{u}-(1-u) c_{e}-G\right)+ \\
& \mu_{4}\left(\phi^{\prime}(s)-\nu(q)(E-U)\right)+\mu_{5}\left((r+s \nu(q)) U-v\left(c_{u}\right)+\phi(s)-s \nu(q) E\right)+ \\
& \mu_{6}\left((r+\lambda+\alpha) E-v\left(c_{e}\right)-(\lambda+\alpha F(R)) U-\alpha(1-F(R)) E_{2}\right)+\mu_{7}\left((r+\lambda) E_{2}-v\left(c_{e}\right)-\lambda U\right)
\end{aligned}
$$

where $\mu_{i}$, for $i \in\{1, \ldots, 7\}$, are the associated costate variables. Notice that the (ICC) is an equality constraint. Since the matrix of partial derivatives of the constraint with respect to the controls has rank equal to one, the constraint qualification holds. The necessary conditions are

$$
\begin{aligned}
\dot{\mu}_{1}=r \mu_{1}-\frac{\partial H}{\partial u} \Leftrightarrow & (r+\lambda+s \nu(q)) \mu_{1}=v\left(c_{u}\right)-\phi(s)-v\left(c_{e}\right)+\mu_{2} s \nu(q) \\
& +\mu_{3}\left(c_{u}-z-c_{e}+\frac{k s}{q}\right)+\dot{\mu}_{1} \\
\dot{\mu}_{2}=r \mu_{2}-\frac{\partial H}{\partial e} \Leftrightarrow & (r+\lambda+\alpha) \mu_{2}=\mu_{1} \alpha F(R)-\mu_{3}\left(\bar{\pi} y+\alpha(1-F(R)) \frac{\mathbb{E} y}{r+\lambda}\right)+\dot{\mu}_{2} \\
\dot{\mu}_{3}=-\frac{\partial H}{\partial A} \Leftrightarrow & \dot{\mu}_{3}=0 \\
\dot{\mu}_{5}=r \mu_{5}-\frac{\partial H}{\partial U} \Leftrightarrow & \left(\mu_{6}+\mu_{7}\right) \lambda+\mu_{6} \alpha F(R)=\left(\mu_{4}+s \mu_{5}\right) \nu(q)+\dot{\mu}_{5} \\
\dot{\mu}_{6}=r \mu_{6}-\frac{\partial H}{\partial E} \Leftrightarrow & \left(\mu_{4}+s \mu_{5}\right) \nu(q)=\mu_{6}(\lambda+\alpha)+\dot{\mu}_{6} \\
\dot{\mu}_{7}=r \mu_{7}-\frac{\partial H}{\partial E_{2}} \Leftrightarrow & \mu_{6} \alpha(1-F(R))=\mu_{7} \lambda+\dot{\mu}_{7}
\end{aligned}
$$


Adding up the last three necessary conditions we obtain

$$
\dot{\mu}_{5}+\dot{\mu}_{6}+\dot{\mu}_{7}=0 \Rightarrow \mu_{5}=-\left(\mu_{6}+\mu_{7}\right)+\psi,
$$

where $\psi$ is a constant. Now, let us focus on the steady state. Notice that the last three conditions indeed coincide with the steady-state conditions of the mass of unemployed $u$, employed $e$ and workers in matches with known quality $1-u-e$. Therefore, $\mu_{4} / s+\mu_{5}=\psi_{0} u, \mu_{6}=\psi_{0} e$ and $\mu_{7}=\psi_{0}(1-u-e)$, where $\psi_{0}$ is a constant different from 1. Putting this together with the above relationship between the costate variables, we have $\mu_{4}=s\left(\psi_{0}-\psi\right)$. Likewise, it follows from equation (71) that $\mu_{3}=-v^{\prime}\left(c_{e}\right)\left(1-\psi_{0}\right)$. Notice that $\psi<0$ follows from bringing together equations (71) and (72), the concavity of the utility function and the incentive-compatibility constraint.

We can now rewrite (73) and (74) as

$$
\begin{aligned}
\mu_{2}-\mu_{1} & =\mu_{3} \frac{k}{q^{2} \nu^{\prime}(q)}+\psi_{0}(E-U) \\
\mu_{1} & =-\mu_{3} \frac{R y}{r+\lambda}-\psi_{0}\left(E_{2}-U\right) \\
\mu_{2} & =\mu_{3}\left(\frac{k}{q^{2} \nu^{\prime}(q)}-\frac{R y}{r+\lambda}\right)+\psi_{0}\left(E-E_{2}\right)
\end{aligned}
$$

where the last equation results from adding up the first two. We now replace these two expressions for the costate variables in necessary conditions (76) and (77) to obtain after some manipulations the constrained efficiency conditions (68) and (69). By replacing the costate variables in condition (75) and isolating the quotient $\frac{\psi-\psi_{0}}{u\left(1-\psi_{0}\right)}$ from conditions (71) and (72), we obtain equation (70).॥

\section{Proof of Proposition 5.2}

We now compare the steady-state equilibrium conditions with its planner's counterparts. It follows from the comparison of the equilibrium and efficiency necessary conditions (30) and (69), respectively, that the implementation of the planner's allocation requires the layoff $\operatorname{tax} L=0$. Likewise, when comparing equations (31) and (68), imposing conditions $c_{u}=z+b-T$ and $c_{e}=$ $w(1-\tau)-T$, we obtain

$$
-\tau\left(\frac{k s}{q} \frac{\varphi(q)}{1-\varphi(q)}+R y\right)=b(1-\tau)
$$




\subsection{Details of the Quantitative Exercise}

\section{Further Details of the Calibration.}

We normalize the market productivity of labor to one. The interest rate is set to be consistent with a $5 \%$ annual interest rate (which leads to $r=0.004$ in the baseline). We set the relative risk aversion as $\sigma=2$, a common value in the literature (we perform robustness checks on this parameter in the next section).

The cost $k$ firms incur when posting vacancies includes both recruiting and training expenses. Hall and Milgrom (2008) calibrate the former to be $14 \%$ of the average quarterly wage per hire. We use information from Abowd and Kramarz (2003), who estimate the recruiting and training costs at $13 \%$ and $7 \%$ of the average quarterly wage per hire, respectively. Thus, we calibrate $k$ to match a ratio of the overall costs of vacancy-posting to average quarterly wages per hire of $20 \%$.

To finance the unemployment insurance system as well as an exogenous public spending $G$ and time-invariant interest on debt $r D$, the government levies a proportional income tax rate $\tau$. Following Krusell et al. (2011), we set the income tax rate at $\tau=0.30$. Regarding benefits $b$, Shimer (2005) assumes a replacement rate of 0.40 while Anderson and Meyer (1997) estimate a pre-tax rate of 0.37 from 1960 to the early 1990s. Although the actual replacement rate in terms of past income is 0.60 , a large number of unemployed workers are not eligible: Anderson and Meyer (1997) estimate that about $40 \%$ of the unemployed file for unemployment benefits. Furthermore, as pointed out by Hornstein et al. (2005), unemployed workers' salaries are below average wages. They report 0.20 as an upper bound for the ratio of benefits to average wages. We follow the suggestion of Hall and Milgrom (2008) and set benefits $b$ to match a benefit to average wage ratio of 0.25 . The sum $G+r D$ accounts for the residual of the budget constraint of the government (see equation (35)), and it amounts to 0.199 or $25.38 \%$ of total output.

To calibrate the value of home productivity $z$, we target the ratio of consumption of the unemployed to the consumption of the employed. Following both Hall and Milgrom (2008) and Kaplan and Menzio (2016), we target a value of 0.85 for this ratio.

The employment-to-unemployment (EU) transitions result either endogenously when match productivity is learned to be low (at rate $\alpha$ times $F(R)$ ) or exogenously when hit by a separation 
shock, which occurs at rate $\lambda$. Thus, we use the dynamics of the EU rates over job tenure together with the monthly EU rate to calibrate parameters $\alpha, \delta$ and $\lambda$. More specifically, we target the ratio of EU rates at the third and sixth quarters of a new employment relationship to the EU rate at the second quarter reported by Choi and Fernández-Blanco (2016) using SIPP data. The monthly EU rate is reported at 0.026 by Menzio and Shi (2011).

Table 2 shows the equilibrium values for the reservation productivity, queue length, wages and search intensity. As seen from the table, $R$ is greater than $1 / \delta=0.3002$, which is the unconditional mean of our chosen productivity distribution. Likewise, wages are above the reservation productivity, meaning that firms make negative profits in a neighborhood of the threshold.

\subsection{Robustness}

We now perform the same policy exercise as in Section 6 for three different scenarios.

\subsubsection{No Government Spending.}

Table 3 shows the quantitative exercise when we restrict attention to the case where $G+r D=0$, and recalibrate the parameters (second column). In the baseline, unemployment benefits $b$ are financed solely with income taxes. Thus, they are set to make the government budget constraint balance period by period. As a result, the income tax rate drops accordingly to $\tau=1.68 \%$. The third column of Table 3 describes the laissez-faire steady state with neither taxes nor benefits. As in the case with government spending, relative to the OP1 and OP2 economies, the absence of unemployment benefits reduces social welfare as well as consumption of both the unemployed and the employed because of less insurance against unemployment risks and a lower output per worker.

Similar to the main quantitative exercise in Table 2, the OP1 economy exhibits the same qualitative results: income taxes are negative, and net benefits and worker turnover are lower and higher than in the baseline and LF economies, respectively.

\subsubsection{Different values of home production.}

The value of home production is a key parameter in search and matching models of the labor market, particularly for policy analysis. We conduct a robustness check by targeting different 


\begin{tabular}{lcccc}
\hline \hline & Baseline & LF & OP2 & OP1 \\
\hline$\quad$ Policy & & & & \\
Lump sum tax & 0.0000 & 0.0000 & 0.0000 & 0.2231 \\
Income tax & 0.0168 & 0.0000 & 0.0033 & -0.4286 \\
Net benefits: $b(1-\tau)-T$ & 0.1261 & 0.0000 & 0.0735 & 0.0616 \\
Implied tax rate: $\tau+T / w$ & 0.0168 & 0.0000 & 0.0033 & 0.0027 \\
\hline$\quad$ Equilibrium & & & & \\
Reservation productivity & 0.4627 & 0.4535 & 0.4573 & 0.4728 \\
Queue length & 15.7821 & 13.2548 & 14.2135 & 19.5590 \\
Wages (before taxes $)$ & 0.5129 & 0.5088 & 0.5105 & 0.5173 \\
Search intensity & 1.1526 & 7.0078 & 3.2726 & 3.7608 \\
\hline$\quad$ Labor market & & & & \\
Unemployment rate & 0.0640 & 0.0102 & 0.0224 & 0.0226 \\
Output per worker & 0.5822 & 0.5778 & 0.5796 & 0.5867 \\
Monthly UE rate & 0.4214 & 0.9694 & 0.7978 & 0.8146 \\
Monthly EU rate & 0.0263 & 0.0088 & 0.0164 & 0.0169 \\
Monthly turnover rate & 0.0551 & 0.0189 & 0.0347 & 0.0357 \\
\hline$\quad$ Welfare & & & & \\
Total output & 0.5449 & 0.5719 & 0.5666 & 0.5735 \\
Consumption unemployed $\left(\chi_{u}\right)$ & 0.4287 & 0.3026 & 0.3761 & 0.3641 \\
Consumption employed $\left(\chi_{e}\right)$ & 0.5043 & 0.5088 & 0.5088 & 0.5158 \\
Ratio $\chi_{u} / \chi_{e}$ & 0.8500 & 0.5947 & 0.7391 & 0.7059 \\
Social Welfare & -277.22 & -274.75 & -273.66 & -272.58 \\
\hline \hline
\end{tabular}

Table 3: Calibrated economy and counterfactual exercises. Note: LF stands for laissez-faire equilibrium; OP1 and OP2 stand for the equilibrium allocations with policy instruments $\{b, \tau, T\}$ and $\{b, \tau\}$, respectively. Turnover rate is defined as hires plus separations over total employment.

consumption ratios $\chi_{u} / \chi_{e}$. For each target, we compare the (recalibrated) baseline steady state and the equilibrium allocation with the optimal fiscal policy $\{b, \tau, T\}$. Table 4 shows the results. The calibrated value of home production $z$ increases with the target for the consumption ratio, which in turn increases the welfare gains from moving to the OP1 economy because less distortionary insurance must be provided publicly. Moreover, calibrated unemployment benefits are excessively generous in all scenarios, while actual worker turnover is too high. The signs of the fiscal instruments are once again in line with the theoretical results.

\subsubsection{Different values of risk aversion.}

Finally, we recalibrate the economy for different values of the risk-aversion parameter and undertake the same policy exercises. The CRRA coefficient $\sigma$ takes values 1,3 and 5 . Table 5 shows the results, which are qualitatively consistent with the previous counterfactual analysis. 


\begin{tabular}{|c|c|c|c|c|c|c|c|c|c|}
\hline & \multicolumn{3}{|c|}{$\begin{array}{c}\chi_{u} / \chi_{e}=0.75 \\
\mathrm{z}=0.2891\end{array}$} & \multicolumn{3}{|c|}{$\begin{array}{c}\chi_{u} / \chi_{e}=0.80 \\
\mathrm{z}=0.3059\end{array}$} & \multicolumn{3}{|c|}{$\begin{array}{c}\chi_{u} / \chi_{e}=0.90 \\
\mathrm{z}=0.3134\end{array}$} \\
\hline & $\mathrm{B}$ & $\mathrm{LF}$ & OP1 & $\mathrm{B}$ & $\mathrm{LF}$ & OP1 & $\mathrm{B}$ & $\mathrm{LF}$ & OP1 \\
\hline Policy & & & & & & & & & \\
\hline Lump sum tax & 0.0000 & 0.0000 & 0.4028 & 0.0000 & 0.0000 & 0.4713 & 0.0000 & 0.0000 & 0.5193 \\
\hline Income tax & 0.3000 & 0.2802 & -0.2022 & 0.3000 & 0.2777 & -0.3103 & 0.3000 & 0.2736 & -0.4375 \\
\hline Net benefits: $b(1-\tau)-T$ & 0.1445 & 0.0000 & 0.0611 & 0.1394 & 0.0000 & 0.0322 & 0.1268 & 0.0000 & -0.0010 \\
\hline Implied tax rate: $\tau+T / w$ & 0.3000 & 0.2802 & 0.2810 & 0.3000 & 0.2777 & 0.2747 & 0.3000 & 0.2736 & 0.2678 \\
\hline Equilibrium & & & & & & & & & \\
\hline Reservation productivity & 0.7449 & 0.7141 & 0.7633 & 0.7181 & 0.6952 & 0.7404 & 0.6537 & 0.6416 & 0.6821 \\
\hline Queue length & 2.2079 & 1.5653 & 2.8187 & 4.7948 & 3.6514 & 6.5483 & 30.3753 & 25.8239 & 47.9542 \\
\hline Wages (before taxes) & 0.8257 & 0.8115 & 0.8336 & 0.7960 & 0.7857 & 0.8054 & 0.7244 & 0.7191 & 0.7363 \\
\hline Search intensity & 0.6771 & 1.8059 & 1.2666 & 0.8351 & 3.0263 & 2.4201 & 1.3750 & 11.9403 & 12.0188 \\
\hline Labor Market & & & & & & & & & \\
\hline Unemployment rate & 0.0640 & 0.0212 & 0.0392 & 0.0640 & 0.0163 & 0.0264 & 0.0640 & 0.0072 & 0.0095 \\
\hline Output per worker & 0.9373 & 0.9221 & 0.9456 & 0.9035 & 0.8925 & 0.9134 & 0.8223 & 0.8166 & 0.8347 \\
\hline Monthly UE rate & 0.4211 & 0.7981 & 0.6162 & 0.4213 & 0.8816 & 0.7671 & 0.4213 & 0.9930 & 0.9854 \\
\hline Monthly EU rate & 0.0262 & 0.0156 & 0.0228 & 0.0263 & 0.0130 & 0.0187 & 0.0263 & 0.0063 & 0.0082 \\
\hline Monthly turnover rate & 0.0550 & 0.0323 & 0.0479 & 0.0551 & 0.0276 & 0.0395 & 0.0551 & 0.0136 & 0.0177 \\
\hline Welfare & & & & & & & & & \\
\hline Total output & 0.8773 & 0.9025 & 0.9085 & 0.8457 & 0.8780 & 0.8893 & 0.7696 & 0.8107 & 0.8268 \\
\hline Consumption unemployed $\left(\chi_{u}\right)$ & 0.4336 & 0.2891 & 0.3502 & 0.4453 & 0.3059 & 0.3381 & 0.4402 & 0.3134 & 0.3125 \\
\hline Consumption employed $\left(\chi_{e}\right)$ & 0.5780 & 0.5841 & 0.5994 & 0.5572 & 0.5675 & 0.5842 & 0.5071 & 0.5223 & 0.5391 \\
\hline Ratio $\chi_{u} / \chi_{e}$ & 0.7501 & 0.4949 & 0.5842 & 0.7991 & 0.5390 & 0.5788 & 0.8681 & 0.6001 & 0.5796 \\
\hline Social Welfare & -209.93 & -210.16 & -204.82 & -227.11 & -222.25 & -217.87 & -274.21 & -260.79 & -256.25 \\
\hline
\end{tabular}

Table 4: Optimal Policy under different calibrations for $z$ (the value of home production). B stands for Baseline, while OP1 is the steady-state allocation of an economy with the optimal $\{b, \tau, T\}$ policy. Turnover rate is defined as hires plus separations over total employment. The gray columns represent the calibration in the benchmark case.

\section{References}

Abowd, J. And F. Kramarz, "The costs of hiring and separations," Labour Economics 10 (2003), 499-530.

Acemoglu, D., "Good jobs versus bad jobs," Journal of labor Economics 19 (2001), 1-21.

Acemoglu, D. And R. Shimer, "Efficient Unemployment Insurance," Journal of Political Economy 107 (Oct. 1999), 893-928.

Alvarez, F. And M. Veracierto, "Severance payments in an economy with frictions," Journal of Monetary Economics 47 (2001), 477-498.

Anderson, P. M. And B. D. Meyer, "Unemployment insurance takeup rates and the after-tax value of benefits," The Quarterly Journal of Economics (1997), 913-937. 


\begin{tabular}{|c|c|c|c|c|c|c|c|c|c|}
\hline & \multicolumn{3}{|c|}{$\sigma=1$} & \multicolumn{3}{|c|}{$\bar{\sigma} \sigma=3$} & \multicolumn{3}{|c|}{$\sigma=5$} \\
\hline & $\mathrm{B}$ & $\mathrm{LF}$ & OP1 & $\mathrm{B}$ & $\mathrm{LF}$ & OP1 & $\mathrm{B}$ & $\mathrm{LF}$ & OP1 \\
\hline Policy & & & & & & & & & \\
\hline Lump sum tax & 0.0000 & 0.0000 & 0.3314 & 0.0000 & 0.0000 & 0.6674 & 0.0000 & 0.0000 & 0.6926 \\
\hline Net benefits: $b(1-\tau)-T$ & 0.0806 & 0.0000 & -0.0279 & 0.1783 & 0.0000 & 0.0508 & 0.2060 & 0.0000 & 0.1164 \\
\hline Implied tax rate: $\tau+T / w$ & 0.3000 & 0.2742 & 0.2672 & 0.3000 & 0.2754 & 0.2716 & 0.3000 & 0.2769 & 0.2763 \\
\hline Equilibrium & & & & & & & & & \\
\hline Queue length & 17.0763 & 14.9596 & 28.0967 & 14.6931 & 11.3568 & 20.5900 & 13.3318 & 8.9934 & 16.6500 \\
\hline Wages (before taxes) & 0.4603 & 0.4575 & 0.4684 & 1.0190 & 1.0065 & 1.0319 & 1.1769 & 1.1535 & 1.1872 \\
\hline Search intensity & 1.1772 & 6.8678 & 9.0876 & 1.1306 & 7.6841 & 5.2547 & 1.1012 & 9.1916 & 3.3739 \\
\hline Labor Market & & & & & & & & & \\
\hline Unemployment rate & 0.0640 & 0.0109 & 0.0109 & 0.0640 & 0.0088 & 0.0168 & 0.0640 & 0.0067 & 0.0241 \\
\hline Output per worker & 0.5224 & 0.5195 & 0.5309 & 1.1565 & 1.1433 & 1.1701 & 1.3357 & 1.3109 & 1.3466 \\
\hline Total output & 0.4890 & 0.5138 & 0.5251 & 1.0825 & 1.1332 & 1.1504 & 1.2502 & 1.3021 & 1.3141 \\
\hline Consumption unemployed $\left(\chi_{u}\right)$ & 0.2738 & 0.1932 & 0.1653 & 0.6063 & 0.4280 & 0.4788 & 0.7002 & 0.4943 & 0.6107 \\
\hline Consumption employed $\left(\chi_{e}\right)$ & 0.3222 & 0.3321 & 0.3432 & 0.7133 & 0.7293 & 0.7516 & 0.8238 & 0.8341 & 0.8592 \\
\hline Ratio $\chi_{u} / \chi_{e}$ & 0.8496 & 0.5818 & 0.4817 & 0.8500 & 0.5868 & 0.6370 & 0.8500 & 0.5926 & 0.7107 \\
\hline Social Welfare & -299.02 & -292.20 & -289.79 & -151.89 & -143.45 & -138.52 & -107.66 & -106.19 & -97.30 \\
\hline
\end{tabular}

Table 5: Optimal Policy under different risk aversion coefficient $\sigma$. B stands for Baseline, while OP1 is the economy with the optimal policy, when instruments $\{b, \tau, T\}$ are chosen. Turnover rate is defined as hires plus separations over total employment. The gray columns represent the calibration in the benchmark case.

Azariadis, C., "Implicit Contracts and Underemployment Equilibria," Journal of Political Economy 83 (1975), pp. 1183-1202.

Baily, M. N., "Wages and Employment under Uncertain Demand," The Review of Economic Studies 41 (1974), pp. 37-50.

Blanchard, O. J. AND J. TiRole, "The joint design of unemployment insurance and employment protection: a first pass," Journal of the European Economic Association 6 (2008), 45-77.

Burdett, K., "Unemployment insurance payments as a search subsidy: a theoretical analysis," Economic Inquiry 17 (1979), 333-343.

Cahuc, P. and A. Zylberberg, "Optimum income taxation and layoff taxes," Journal of Public Economics 92 (2008), 2003 - 2019.

Chetty, R., "Moral Hazard versus Liquidity and Optimal Unemployment Insurance," Journal of Political Economy 116 (2008), 173-234. 
Choi, S. and J. Fernández-Blanco, "A note on US worker turnover," Oxford Bulletin of Economics and Statistics (forthcoming) (2016).

FArber, H. S., "Mobility and stability: The dynamics of job change in labor markets," Handbook of labor economics 3 (1999), 2439-2483.

Feldstein, M., "The Effect of Unemployment Insurance on Temporary Layoff Unemployment," The American Economic Review 68 (1978), pp. 834-846.

Golosov, M., P. Maziero And G. Menzio, "Taxation and Redistribution of Residual Income Inequality," Journal of Political Economy 121 (2013), 1160-1204.

Hall, R. And P. Milgrom, "The Limited Influence of Unemployment on the Wage Bargain," The American Economic Review 98 (2008), 1653-1674.

Hopenhayn, H. A. And J. P. Nicolini, "Optimal unemployment insurance," Journal of political economy 105 (1997), 412-438.

Hornstein, A., P. Krusell and G. L. Violante, "Unemployment and vacancy fluctuations in the matching model: inspecting the mechanism," Federal Reserve Bank of Richmond Economic Quarterly 91 (2005), 19-51.

JACQUET, N. L. AND S. TAN, "Wage-vacancy contracts and coordination frictions," Journal of Economic Theory 147 (2012), 1064-1104.

Jovanovic, B., "Job matching and the theory of turnover," The Journal of Political Economy 87 (1979), 972-990.

—_, "Matching, turnover, and unemployment," The Journal of Political Economy (1984), 108122.

Kaplan, G. And G. Menzio, "Shopping Externalities and Self-Fulfilling Unemployment Fluctuations," Journal of Political Economy 124 (2016), 771-825.

Krishna, V., Auction theory (Academic Press, 2009). 
Krusell, P., T. Mukoyama And A. Ahin, "Labour-Market Matching with Precautionary Savings and Aggregate Fluctuations," Review of Economic Studies 77 (2010), 1477-1507.

Krusell, P., T. Mukoyama, R. Rogerson and A. Şahin, "A three state model of worker flows in general equilibrium," Journal of Economic Theory 146 (2011), 1107-1133.

LAmAdOn, T., "Productivity shocks, dynamic contracts and income uncertainty," working paper (2014).

Marimon, R. And F. Zilibotti, "Unemployment vs. mismatch of talents: reconsidering unemployment benefits," The Economic Journal 109 (1999), 266-291.

Menzio, G. And S. ShI, "Efficient Search on the Job and the Business Cycle," Journal of Political Economy 119 (2011).

Meyer, B. D., "Unemployment Insurance and Unemployment Spells," Econometrica 58 (1990), $757-782$.

Mitman, K. And S. Rabinovich, "Optimal unemployment insurance in an equilibrium businesscycle model," Journal of Monetary Economics 71 (2015), 99 - 118.

Moen, E. R., "Competitive search equilibrium," Journal of Political Economy 105 (1997), 385411.

Moen, E. R. And Å. Rosén, "Does poaching distort training?," The Review of Economic Studies 71 (2004), 1143-1162.

Moscarini, G., "Skill and Luck in the Theory of Turnover," working paper (2003).

— , "Job matching and the wage distribution," Econometrica 73 (2005), 481-516.

Nelson, P., "Information and consumer behavior," The Journal of Political Economy (1970), $311-329$.

Pinheiro, R. AND L. Visschers, "Unemployment risk and wage differentials," working paper (2014). 
Pries, M. And R. Rogerson, "Hiring policies, labor market institutions, and labor market flows," Journal of Political Economy 113 (2005), 811-839.

RudAnKo, L., "Labor market dynamics under long-term wage contracting," Journal of Monetary Economics 56 (2009), 170-183.

Shimer, R., "The Cyclical Behavior of Equilibrium Unemployment and Vacancies," American Economic Review 95 (2005), 25-49.

Shimer, R., R. And I. Werning, "Liquidity and Insurance for the Unemployed," American Economic Review 98 (2008), 1922-1942.

Teulings, C. N. And P. A. Gautier, "The right man for the job," The Review of Economic Studies 71 (2004), 553-580.

Wang, C. And S. D. Williamson, "Moral hazard, optimal unemployment insurance, and experience rating," Journal of Monetary Economics 49 (2002), 1337-1371. 